Prof. Ximena Gauché Marchetti*

\title{
Pensando en los cambios a la educación en Chile desde el paradigma internacional de la Educación en Derechos Humanos ${ }^{1}$ Thinking about changes to education in Chile from the international paradigm of Human Rights Education
}

\begin{abstract}
Resumen
El presente artículo busca presentar en qué consiste la "educación en derechos humanos", que sería conveniente por lo menos tomar en cuenta al empezar a re-construir el derecho fundamental a la educación en Chile con miras al tercer centenario y los próximos cien años de derecho público en el país. Para ello se presenta el contenido que tiene esta idea de la "educación en derechos humanos" y su reconocimiento en la institucionalidad internacional, mostrando los dos desarrollos concretos mencionados. Antes en todo caso, el tema se introduce desde los problemas de justiciabilidad que enfrentan los derechos económicos, sociales y culturales y el reconocimiento normativo que tiene el derecho a la educación en el ámbito del Derecho Internacional, en cuanto disciplina que guía este trabajo.
\end{abstract}

*Doctora en Derecho, Programa de Doctorado en Derecho Internacional y Relaciones Internacionales, Universidad Autónoma de Madrid.

Profesora Asociada, Facultad de Ciencias Juridicas y Sociales, Universidad de Concepción. xgauche@gmail.com

\section{Palabras clave}

Educación - derechos humanos - derecho internacional

Artículo redactado en base a la ponencia presentada por la autora en las XLI Jornadas Chilenas de Derecho Público "200 años de Derecho Público Chileno 1811 -2011", Facultad de Derecho, Universidad de Chile, en Santiago de Chile, los días jueves 24 y viernes 25 de noviembre de 2011. Versión final revisada al 28 de febrero de 2012. 


\begin{abstract}
This article aims to present the "human rights education", which could be appropriate to take into account when starting to re -build the fundamental right to education in Chile with a view to the third centenary and the next one -hundred years of public law in the country. Here we present the content of this idea of "human rights education" and its recognition in the international system, showing the two specific developments mentioned. Earlier in any case, the topic is introduced from the problems faced justiciability of economic, social and cultural rights and the recognition policy that has the right to education in the field of international law, as a discipline that guides this paper.
\end{abstract}

\title{
Keywords
}

Education - human rights - international law

\section{Los problemas de justiciabilidad de los derechos económicos, sociales y culturales, a modo de introducción.}

La educación y el derecho a ella se ha convertido en un tema eje de las discusiones sobre derechos humanos y específicamente sobre los derechos económicos, sociales y culturales y cómo dotarlos de efectiva garantía o hacerlos verdaderamente justiciables.

La introducción a este tema suele acompañarse de la ya clásica caracterización de los derechos fundamentales a partir de "generaciones de derechos", agrupación que se haría según el momento en que han surgido y el valor protegido que tienden a realizar y en mérito de la cual -en una simplificación sólo para estos efectos introductoriosserían derechos "de primera generación" aquellos asociados a la libertad y nacidos en el seno de los procesos revolucionarios de la segunda mitad del siglo XIX; derechos "de segunda generación" los asociados a la igualdad-grupo en que estaría el derecho a la educación- y que encuentran su origen en el cambio del modelo de Estado y las primeras reivindicaciones de una nueva clase social; y derechos "de tercera generación", los vinculados a la solidaridad que se asocia al tiempo que nace tras la segunda guerra mundial y la consideración del bienestar de las generaciones futuras.

Frente a esta opción, sin embargo, hay que apuntar que la idea de clasificar los derechos por "generaciones" dando contornos específicos a cada una de estas "generaciones" -o más o menos específicos si se piensa que podrían existir nuevas "generaciones", más allá de la cuarta incluso-, es un desarrollo que en buena medida ha ido quedando relegado con la consagración cada vez de forma más fuerte de la unidad e indivisibilidad de los derechos, pero que no obstante ello puede resultar útil para entender los orígenes de 
cada tipo de derechos y algunas de las características que a cada uno se atribuyen y que están o pueden estar en la base de las argumentaciones que justifican en las diferencias estructurales entre los distintos tipos de derechos los problemas de justiciabilidad que tienen los económicos, sociales y culturales.

En ese sentido, los derechos de segunda generación serían aquellos que surgen con el nacimiento de un nuevo modelo de Estado: el Estado de Bienestar, enmarcado en un tiempo bien concreto que es el inicio del siglo $\mathrm{XX}^{2}$. Aspiran a satisfacer para sus titulares ciertas condiciones materiales básicas, como la salud, el trabajo o la educación, estimadas indispensables para lograr la igualdad entre los miembros de la familia humana y enmarcadas en una concepción material de la democracia, desarrollada a partir de la toma de conciencia de una nueva clase social -el proletariado- y de que hay una situación de desigualdad en la riqueza y su distribución que se traduce en una contradicción entre el reconocimiento formal de los derechos y las necesidades o carencias materiales para su adecuado ejercicio.

Este grupo de derechos incluye entonces a los derechos económicos, sociales y culturales, entre los cuales la educación es uno de los principales. Si se requiere caracterizarlos desde esta mirada tradicional habría que decir que se les concibe como derechos de prestación, es decir, suponen una actitud positiva del Estado; son de titularidad individual, pero con una inspiración empírica del individuo, lo que significa que miran al ser humano contextualizado como trabajador, enfermo o estudiante, por ejemplo, y no como un ser abstracto como se miraría desde los derechos de libertad; son derechos que remiten a un concepto de libertad pero que se estima configurado a partir de la igualdad; y pueden ser considerados como un elemento que ayuda al ejercicio más pleno de la ciudadanía desde una perspectiva social de ella, y a la cohesión social. Este último rasgo por cierto es uno que marca importantes diferencias para la sociedad en la perspectiva de unos u otros derechos cuando se les compara con los de "primera generación”" . En efecto "...mientras que los primeros se sustentan en una clara filosofía individualista, en una concepción del individuo como ente abstracto, la filosofía que sostiene

\footnotetext{
Puede estimarse más o menos consensuado que el sustrato ideológico de estos derechos está en el pensamiento marxista y en la nueva socialdemocracia que empieza a consolidarse a inicios del siglo XX, en el contexto de la llamada "Cuestión Social" en cuanto fenómeno social, encontrando sus primeros reconocimientos jurídicos en la Constitución de México de 1917, la Alemana de Weimar de 1919, la Espańola de 1931 y las constituciones rusas de 1918 y 1936, desde donde se extenderían con el correr del siglo a la mayoría de los textos constitucionales.

3 Derechos "de primera generación" en la visión tradicional serían aquellos que primero encuentran reconocimiento jurídico y se enmarcan en el tiempo de las reivindicaciones surgidas a partir de los procesos revolucionarios del siglo XVIII y que aspiraban a satisfacer para los titulares respecto de quienes se reclama el derecho básico a la libertad, expresada en un primer momento en la posibilidad de participar políticamente en la formación de las decisiones que a todo el pueblo afectaban. Constituyeron un elemento de transformación de la sociedad y del Estado al contribuir en el derrumbe del Estado "absolutista", siendo la base de un nuevo modelo: el Estado "garantista" que sólo establece medios de protección, sin entrometerse en las acciones y actividades de los sujetos. Se dice en general que deben ser tutelados por el Estado mediante un "dejar hacer", actuando como Estado neutro y pasivo. Son derechos "de primera generación" los derechos civiles y políticos, enmarcados en la democracia como cuestión formal, lo cual lleva a que se mire a su reconocimiento por igual para todos, sin importar las condiciones reales del sujeto. Si se quiere caracterizarlos habría que decir que son derechos de titularidad individual y de inspiración individualista; de defensa o de autonomía, en el sentido que establecen un límite al actuar del Estado; y tienen como fundamento el valor de la libertad, tanto en su expresión negativa como positiva.
} 
a los segundos es una filosofía más gregaria, más societaria, que tiene en consideración la diversa situación de los ciudadanos. Frente al individuo átomo, una perspectiva social, colectiva. Los derechos sociales, derechos de prestación, son parte del mecanismo por el cual el individuo es, no aislado, sino absorbido por la sociedad, permitiéndole beneficiarse y, al mismo tiempo, contribuir al bienestar colectivo (politicas de promoción social, políticas fiscales). En cuanto mecanismo de integración, los derechos sociales desempeñan un papel decisivo en la preservación de la cohesión social'4.

Centrándose en su reconocimiento, promoción y protección, hay que remarcar la idea que se predica de ellos tradicionalmente en orden a que la tutela del Estado tiene que materializarse a través de un actuar positivo que suponga la creación de las condiciones mínimas para su satisfacción. De ahí que su reconocimiento traería aparejado la incorporación de un actor especial y primer obligado -no único si tomamos una perspectiva que atribuya un rol a los particulares como empresas, por ejemplo-, que será el gobierno y la administración del Estado, que tendrá que llevar adelante una actuación adecuada para cumplir con entregar las condiciones materiales necesarias. En esa lógica clásica, se estima que los derechos económicos, sociales y culturales son relativos por su carácter prestacional, dependiendo en consecuencia de los recursos económicos de cada país para su realización, los cuales son evidentemente diversos entre sí y aun para cada Estado según la época de que se trate. Consecuente con ello, habría en este punto una diferencia sustancial con los derechos civiles y políticos y se trataría no en verdad de "derechos" sino de "normas programáticas" que pueden recoger las constituciones según las orientaciones de ella en un momento dado y que podrán materializarse o no dependiendo en buena medida de la economía y los recursos financieros del Estado. Como apunta en esta línea el profesor Nogueira respecto de quienes dan estas argumentaciones, "la doctrina considera que los derechos económicos, sociales y culturales constituyen parte de la politica social que realizan los gobiernos dependiendo de los procesos económicos financieros del Estado, por lo que carecen de garantías efectivas" 5 . Amparándose en este tipo de razonamientos es que se les ha tratado más bien desde las políticas públicas, como cuestión relacionada al crecimiento como país y los beneficios que puede entregar un Estado para satisfacer las necesidades de la población, más que como derechos que los integrantes de esa población tienen y pueden exigir.

Dicho lo anterior, hay que apuntar que la diferente concepción que se ha defendido tradicionalmente de cada una de estas dos "generaciones" y el rol que se ha atribuido al Estado frente a ellas se ha traducido normativamente en diferentes medios de protección y tratamiento. Prueba de ello en el plano internacional es la existencia de dos tratados internacionales para protegerlos, los cuales establecen a su vez diferentes mecanismos de protección: el Pacto Internacional de Derechos Civiles y Políticos y el

\footnotetext{
Martínez De Pisón, J. Derechos Humanos: historia, fundamento y realidad, Egido Editorial, 1997, p. 188. Nogueira, H. "Los derechos económicos, sociales y culturales como derechos fundamentales efectivos en el constitucionalismo democrático latinoamericano", en Revista Estudios Constitucionales, Año 7, No 2, 2009, pp. $12-13$.
} 
Pacto Internacional de Derechos Económicos, Sociales y Culturales, ambos de 1966 y en vigor desde 1976.

Sin embargo, desde la consagración de la indivisibilidad e interdependencia ${ }^{6}$ y también de la idea de la necesidad de justiciabilidad para toda clase de derechos, es decir, la posibilidad de reclamar en sede jurisdiccional frente a un incumplimiento, hoy buena parte de la doctrina y la propia institucionalidad internacionalidad estima que el Estado debe asumir un rol activo tanto en la satisfacción de los derechos civiles y políticos como de los derechos económicos, sociales y culturales, y que el carácter prestacional está presente en todos, sin que las argumentadas razones de carácter económico puedan usarse como excusa estatal frente a los segundos que, como mínimo, requieren el compromiso y el trabajo para un desarrollo progresivo y no regresivo en cada sociedad nacional; así como el ámbito de la libertad o del dejar hacer está también presente en la mayoría de los derechos.

Desde el derecho internacional el Comité de Derechos Económicos, Sociales y Culturales de Naciones Unidas ha sostenido: "[... ] A este respecto, es importante distinguir entre justiciabilidad (que se refiere a las cuestiones que pueden o deben resolver los tribunales) y las normas de aplicación inmediata (que permiten su aplicación por los tribunales sin más disquisiciones). Aunque sea necesario tener en cuenta el planteamiento general de cada uno de los sistemas juridicos, no hay ningún derecho reconocido en el Pacto que no se pueda considerar que posee en la gran mayoría de los sistemas algunas dimensiones significativas, por lo menos de justiciabilidad. A veces se ha sugerido que las cuestiones que suponen una asignación de recursos deben remitirse a las autoridades politicas y no a los tribunales. Aunque haya que respetar las competencias respectivas de los diversos poderes, es conveniente reconocer que los tribunales ya intervienen generalmente en una gama considerable de cuestiones que tienen consecuencias importantes para los recursos disponibles. La adopción de una clasificación rígida de los derechos económicos, sociales y culturales que los sitúe por definición fuera del ámbito de los tribunales, sería, por lo tanto, arbitraria e incompatible con el principio de que los dos grupos de derechos son indivisibles e interdependientes. También se reduciria drásticamente la capacidad de los tribunales para proteger los derechos de los grupos más vulnerables y desfavorecidos de la sociedad"7. A estos pronunciamientos hay que sumar la idea de que no sólo los recursos en sede jurisdiccional pueden con-

6 La indivisibilidad de los derechos humanos es una característica asumida con fuerza a partir de la Declaración de Teherán de 1968, emanada de la Primera Conferencia Mundial de los Derechos Humanos celebrada para evaluar los logros en los primeros veinte años de vida de la Declaración Universal de Derechos Humanos de 1948, que establece que todos los derechos están relacionados entre sí, sin que pueda existir una jerarquía entre ellos. Dice este instrumento en su párrafo 13: "Como los derechos humanos y las libertades fundamentales son indivisibles, la realización de los derechos civiles y politicos, sin el goce de los derechos económicos, sociales y culturales resulta imposible". Al tiempo después, la Asamblea General de Naciones Unidas en la Resolución 32/130, de 16 de diciembre de 1977, señalaba que "todos los derechos humanos y libertades fundamentales son indivisibles e interdependientes”, debiendo prestarse la misma atención y urgente consideración a la aplicación, promoción y protección tanto de los derechos civiles y políticos como de los económicos, sociales y culturales, idea que se reiteró en la Conferencia Mundial de Derechos Humanos de Viena, en 1993, en el punto I.5 de la Declaración y Programa de Viena adoptada como resultado de dicha conferencia.

Observación General N 9, E/C. 12/1998/24, 3 de diciembre de 1998, párrafo 10. 
tribuir a la justiciabilidad, si tomamos esta en un sentido más amplio. En efecto, dice el órgano que el derecho a un recurso efectivo "no debe interpretarse necesariamente en el sentido de que exige siempre un recurso judicial. Los recursos administrativos en muchos casos son adecuados, y quienes viven bajo la jurisdicción de un Estado Parte tienen la expectativa legitima de que, sobre la base del principio de buena fe, todas las autoridades administrativas, al adoptar decisiones, tendrán en cuenta las disposiciones del Pacto" ${ }^{\text {. Por }}$ cierto que tales recursos administrativos deben ser accesibles, no onerosos, rápidos y eficaces, resultando conveniente muchas veces establecer un derecho último de apelación judicial con respecto a los procedimientos administrativos de este tipo. En último término, la justiciabilidad y el camino a ella se relaciona con el carácter progresivo y jamás regresivo que deben tener las obligaciones en este ámbito.

En la doctrina nacional chilena en tanto, y situado en la concepción que considera la existencia de un bloque constitucional de derechos, desde que los constitucionalismos latinoamericanos se han distinguido en el concierto internacional en las últimas tres décadas por asegurar los derechos fundamentales con base no sólo en la explicitación formal de los derechos asegurados constitucionalmente sino también incorporando a estos los derechos asegurados por las fuentes formales del derecho internacional, el profesor Humberto Nogueira señala en relación a este punto "... Lo trascendente es que el ordenamiento jurídico asegure los derechos sociales y sus instituciones garantizadoras administrativas y jurisdiccionales, como normas juridicas vinculantes y de efecto directo al menos en su contenido esencial, además del contenido minimo de tales derechos asegurado por el derecho internacional; se desarrollen acciones jurisdiccionales idóneas para la protección de tales derechos; se establezcan limites a la autonomía de la voluntad y a la autonomía contractual en base al respeto de los derechos fundamentales; se institucionalice la función del Estado de promotor de tales derechos y de regulador del ámbito privado.

Ello obliga a fortalecer el Estado Constitucional democrático como nueva aproximación que fortalezca los derechos y sus garantías y consolide los principios de supremacia constitucional y de imperio de la juridicidad, la publicidad de las actuaciones del poder público y el control del poder" ${ }^{\prime}$.

Como se ve, no resulta hoy sostenible -y esa es la opción en este trabajo- defender diferencias estructurales en que ampararse para justificar la falta de garantía que los afecta. En último término, parece fácil dar por acreditado que de alguna manera para la satisfacción de los derechos civiles y políticos también se requieren actuaciones positivas y en ese sentido, tienen también carácter prestacional, así como para los derechos sociales es también necesaria a veces la omisión de los poderes públicos. Efectivamente, para garantizar la participación política es necesario contar con la implementación de un adecuado sistema electoral; para lograr igualdad ante la ley, acceso a la justicia por medio de un recurso cierto y efectivo, y derecho al debido proceso, se debe contar

Observación General N 9, E/C. 12/1998/24, 3 de diciembre de 1998, párrafo 9.

Nogueira, H. "Los derechos económicos, sociales y culturales como derechos fundamentales efectivos en el constitucionalismo democrático latinoamericano” (cit.) p. 145. 
con un correcto sistema judicial; y para garantizar el derecho a huelga o la libertad sindical -clásicos derechos "de segunda generación"- se requiere, como un elemento, la pasividad del Estado, es decir, el famoso "dejar hacer".

A continuación y desde esta posición, daré una mirada al derecho a la educación en el derecho internacional para llegar luego a presentar la educación en derechos humanos que quiere destacar este artículo como paradigma.

\section{El contenido, reconocimiento y garantía del derecho a la educación en los sistemas internacionales de protección de derechos humanos, con referencia al sistema universal y al sistema interamericano.}

En el marco de los sistemas internacionales de protección de derechos humanos son muchos los tratados e instrumentos que han ido incorporando disposiciones referidas a la educación y el derecho a ella. De estas se puede extraer el contenido o atributos que se entienden incluidos en este derecho, su reconocimiento y los mecanismos de garantía y, por cierto, desde ya permiten adelantar la conclusión de que el Derecho Internacional de los Derechos Humanos lo considera jurídicamente vinculante, en el marco mayor que supone aceptar con ese carácter la existencia de los derechos económicos y sociales en general.

Situándonos en el origen de estos sistemas con la adopción de la Declaración Universal de los Derechos Humanos el 10 de diciembre de $1948^{10}$, se establece en el artículo 26 el derecho de toda persona a la educación, la gratuidad al menos en la instrucción elemental y que su objeto es el pleno desarrollo de la personalidad humana y el respeto de los derechos humanos y las libertades fundamentales ${ }^{11}$.

Más adelante, el artículo $7^{\circ}$ de la Convención Internacional sobre la Eliminación de todas las formas de Discriminación Racial de 1965 (CDR) ${ }^{12}$; el artículo 13 del Pacto

10 Resolución 217 A de la Asamblea General de Naciones Unidas.

11 "1. Toda persona tiene derecho a la educación. La educación debe ser gratuita, al menos en lo concerniente a la instrucción elemental y fundamental. La instrucción elemental será obligatoria. La instrucción técnica y profesional habrá de ser generalizada; el acceso a los estudios superiores será igual para todos, en función de los méritos respectivos. 2. La educación tendrá por objeto el pleno desarrollo de la personalidad humana y el fortalecimiento del respeto a los derechos humanos y a las libertades fundamentales; favorecerá la comprensión, la tolerancia y la amistad entre todas las naciones y todos los grupos étnicos o religiosos, y promoverá el desarrollo de las actividades de las Naciones Unidas para el mantenimiento de la paz. 3. Los padres tendrán derecho preferente a escoger el tipo de educación que habrá de darse a sus hijos".

12 "Los Estados partes se comprometen a tomar medidas inmediatas y eficaces, especialmente en las esferas de la enseñanza, la educación, la cultura y la información, para combatir los prejuicios que conduzcan a la discriminación racial y para promover la comprensión, la tolerancia y la amistad entre las naciones y los diversos grupos raciales o étnicos, así como para propagar los propósitos y principios de la Carta de las Naciones Unidas, de la Declaración Universal de Derechos Humanos, de la Declaración de las Naciones Unidas sobre la eliminación de todas las formas de discriminación racial y de la presente Convención". Chile firmó esta Convención el 3 de octubre de 1966 y la ratificó el 20 de octubre de 1971. Por declaración del 18 de mayo de 1994 reconoció la competencia del Comité para la Eliminación de 
Internacional de Derechos Económicos, Sociales y Culturales de 1966 (PIDESC) ${ }^{13}$; el artículo 10 de la Convención sobre la eliminación de toda forma de discriminación contra la mujer de 1979 (CEDAW) ${ }^{14}$; y los artículos 28 y 29 de la Convención de Derechos del Niño de 1989 (CDN) $)^{15}$ le han otorgado un espacio relevante; por citar

la Discriminación Racial para recibir comunicaciones individuales en que se alegue que Chile ha violado alguno de los derechos reconocidos en el pacto.

13 "1. Los Estados Partes en el presente Pacto reconocen el derecho de toda persona a la educación. Convienen en que la educación debe orientarse hacia el pleno desarrollo de la personalidad humana y del sentido de su dignidad, y debe fortalecer el respeto por los derechos humanos y las libertades fundamentales. Convienen asimismo en que la educación debe capacitar a todas las personas para participar efectivamente en una sociedad libre, favorecer la comprensión, la tolerancia y la amistad entre todas las naciones y entre todos los grupos raciales, étnicos o religiosos, y promover las actividades de las Naciones Unidas en pro del mantenimiento de la paz. 2. Los Estados Partes en el presente Pacto reconocen que, con objeto de lograr el pleno ejercicio de este derecho: a) La enseñanza primaria debe ser obligatoria y asequible a todos gratuitamente; b) La enseñanza secundaria, en sus diferentes formas, incluso la enseñanza secundaria técnica y profesional, debe ser generalizada y hacerse accesible a todos, por cuantos medios sean apropiados, y en particular por la implantación progresiva de la enseñanza gratuita; c) La enseñanza superior debe hacerse igualmente accesible a todos, sobre la base de la capacidad de cada uno, por cuantos medios sean apropiados, y en particular por la implantación progresiva de la enseñanza gratuita; d) Debe fomentarse o intensificarse, en la medida de lo posible, la educación fundamental para aquellas personas que no hayan recibido o terminado el ciclo completo de instrucción primaria; e) Se debe proseguir activamente el desarrollo del sistema escolar en todos los ciclos de la enseñanza, implantar un sistema adecuado de becas, y mejorar continuamente las condiciones materiales del cuerpo docente. 3. Los Estados Partes en el presente Pacto se comprometen a respetar la libertad de los padresy, en su caso, de los tutores legales, de escoger para sus hijos o pupilos escuelas distintas de las creadas por las autoridades públicas, siempre que aquéllas satisfagan las normas minimas que el Estado prescriba o apruebe en materia de enseñanza, y de hacer que sus hijos o pupilos reciban la educación religiosa o moral que esté de acuerdo con sus propias convicciones. 4. Nada de lo dispuesto en este artículo se interpretará como una restricción de la libertad de los particulares y entidades para establecer y dirigir instituciones de enseñanza, a condición de que se respeten los principios enunciados en el párrafo 1 y de que la educación dada en esas instituciones se ajuste a las normas mínimas que prescriba el Estado". Chile firmó este Pacto el 16 de septiembre de 1969 y lo ratificó el 10 de febrero de 1972.

14 "Los Estados Partes adoptarán todas las medidas apropiadas para eliminar la discriminación contra la mujer, a fin de asegurarle la igualdad de derechos con el hombre en la esfera de la educación y en particular para asegurar, en condiciones de igualdad entre hombres y mujeres: a) Las mismas condiciones de orientación en materia de carreras y capacitación profesional, acceso a los estudios y obtención de diplomas en las instituciones de enseñanza de todas las categorias, tanto en zonas rurales como urbanas; esta igualdad deberá asegurarse en la enseñanza preescolar, general, técnica, profesional y técnica superior, así como en todos los tipos de capacitación profesional; b) Acceso a los mismos programas de estudios, a los mismos exámenes, a personal docente del mismo nivel profesional y a locales y equipos escolares de la misma calidad; c) La eliminación de todo concepto estereotipado de los papeles masculino y femenino en todos los niveles y en todas las formas de enseñanza, mediante el estímulo de la educación mixta y de otros tipos de educación que contribuyan a lograr este objetivo y, en particular, mediante la modificación de los libros y programas escolares y la adaptación de los métodos de enseñanza; d) Las mismas oportunidades para la obtención de becas y otras subvenciones para cursar estudios; e) Las mismas oportunidades de acceso a los programas de educación permanente, incluidos los programas de alfabetización funcionaly de adultos, con miras en particular a reducir lo antes posible toda diferencia de conocimientos que exista entre hombres y mujeres; $f$ ) La reducción de la tasa de abandono femenino de los estudios y la organización de programas para aquellas jóvenes y mujeres que hayan dejado los estudios prematuramente; g) Las mismas oportunidades para participar activamente en el deporte y la educación fisica; h) Acceso al material informativo especifico que contribuya a asegurar la salud y el bienestar de la familia, incluida la información y el asesoramiento sobre planificación de la familia". Chile firmó esta Convención el 17 de julio de 1980 y la ratificó el 7 de diciembre de 1989, firmando su Protocolo Facultativo el 10 de diciembre de 1999 pero a noviembre de 2011 aún no lo ha ratificado.

15 Artículo 28. "1. Los Estados Partes reconocen el derecho del niño a la educación y, a fin de que se pueda ejercer progresivamente y en condiciones de igualdad de oportunidades ese derecho, deberán en particular: a) Implantar la enseñanza primaria obligatoria y gratuita para todos; b) Fomentar el desarrollo, en sus distintas formas, de la enseñanza secundaria, incluida la enseñanza general y profesional, hacer que todos los niños dispongan de ella y tengan acceso a ella y adoptar medidas apropiadas tales como la implantación de la enseñanza gratuita y la concesión de asistencia financiera en caso de necesidad; c) Hacer la enseñanza superior accesible a todos, sobre la base de la capacidad, por cuantos medios sean apropiados; d) Hacer que todos los niños dispongan de información y orientación en cuestiones educacionales y 
los principales acuerdos vinculantes de derechos humanos con vocación universal que han reconocido este derecho.

A ellos hay que sumar el reconocimiento y la labor de promoción que ha venido a plasmarse en instrumentos de menor valor normativo, incluidos en lo que consideramos como "soft law", muchos de ellos emanados de las sendas conferencias que se celebraron en décadas pasadas.

En este grupo, importantes aportes para la causa de la educación como derecho han sido, por ejemplo, la Declaración y Programa de Acción de Viena, surgido de la Segunda Conferencia Mundial de Derechos Humanos de Viena en 1993; así como la incorporación del tema de la capacitación y educación de la mujer en la Plataforma de Beijing, emanada de la Cuarta Conferencia Mundial sobre la Mujer, en 1995; en los Objetivos de Desarrollo del Milenio que contempló a la educación primaria universal como el segundo de ellos en el año 2000; y la Declaración y Programa de Acción de la Conferencia Mundial contra el Racismo, la Discriminación Racial, la Xenofobia y las formas conexas de Intolerancia, celebrada en Durbán, Sudáfrica, en 2001. A ellos hay que agregar el importante desarrollo que surgió en Jomtien, Tailandia, entre el 5 y el 9 de marzo de 1990, al adoptarse la Declaración Mundial sobre Educación para todos "Satisfacción de las necesidades básicas de aprendizaje" en que se definió un conjunto de herramientas esenciales para el aprendizaje y los contenidos básicos de aprendizaje

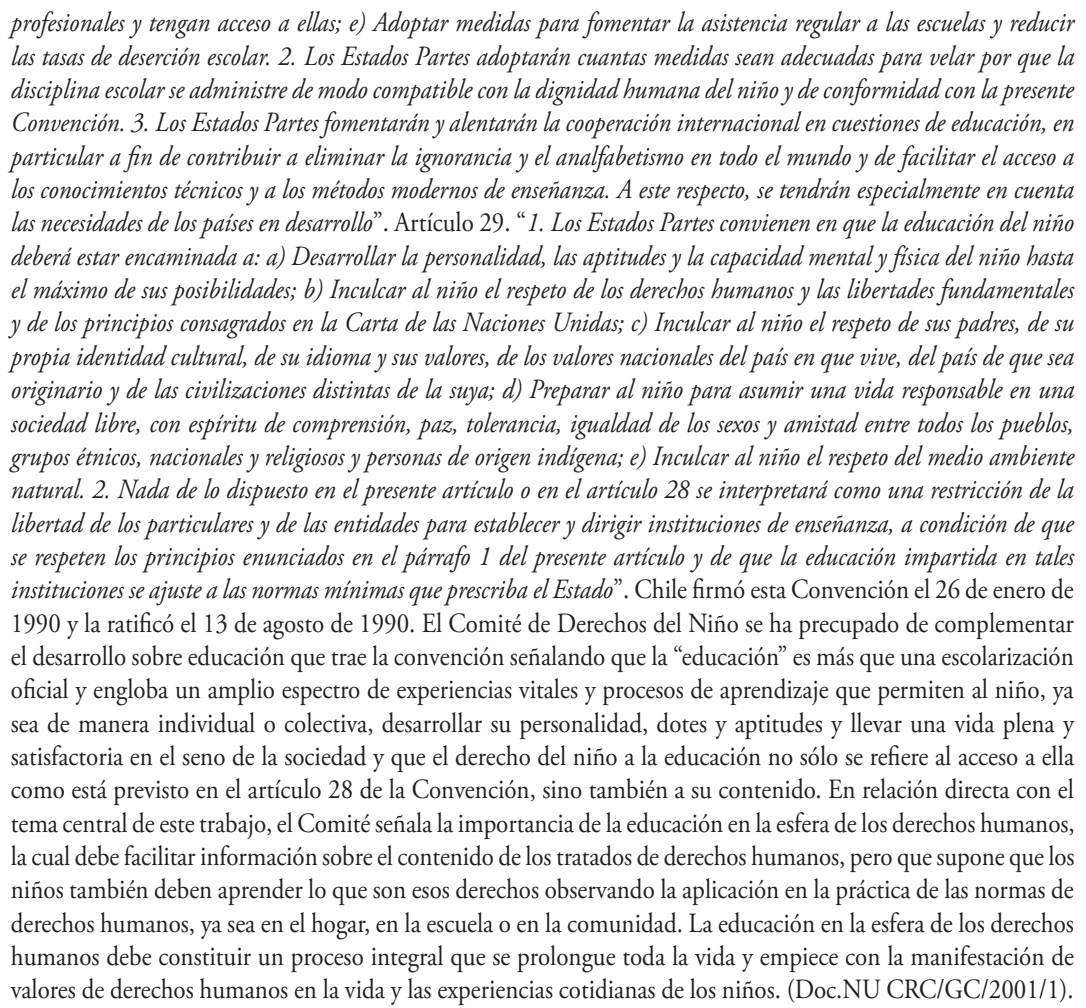


(conocimientos prácticos y teóricos, valores y actitudes) que se necesitan para que los seres humanos puedan sobrevivir, desarrollar plenamente sus capacidades, vivir y trabajar con dignidad, participar plenamente en el desarrollo, mejorar la calidad de vida, tomar decisiones fundamentadas y continuar aprendiendo.

La educación entonces es un tema central en los trabajos sobre derechos humanos, prueba de lo cual es que en abril de 1998 la entonces Comisión de Derechos Humanos creó la Relatoría Especial sobre el Derecho a la Educación ${ }^{16}$, mantenida por el Consejo de Derechos Humanos ${ }^{17}$, que contempla en el mandato visitas a los países parte; recibir quejas individuales sobre violaciones a este derecho; y dialogar con los gobiernos, la sociedad civil y otro actores relevantes para ir identificando soluciones a los problemas del derecho a la educación.

De todo ese trabajo normativo e institucional a favor de la educación en el sistema de Naciones Unidas rescato como principal el artículo 13 del PIDESC, ya que contiene uno de los mayores desarrollos sobre la educación en el ámbito jurídico internacional, sobre cuyas bases trabaja esencialmente el Relator Especial ya citado, y que ha sido complementado por el trabajo del órgano de vigilancia del Pacto, el Comité de los Derechos Económicos, Sociales y Culturales de Naciones Unidas ${ }^{18}$ que, por ejemplo, ha establecido claramente los estándares que debe cumplir la educación en todo Estado. Disponibilidad (instituciones y programas de enseńanza en cantidad suficiente); accesibilidad (que comprende la no discriminación, la accesibilidad material y la accesibilidad económica); aceptabilidad (la forma y el fondo de la educación deben ser aceptables); y adaptabilidad (la educación ha de tener la flexibilidad necesaria para adaptarse a las necesidades de sociedades y comunidades en transformación y de los alumnos en contextos culturales y sociales variados).

Específicamente en el ámbito de la accesibilidad el Comité ha dicho en su Observación General No 13, de 8 de diciembre de $1999^{19}$, que la educación en cualquiera de sus niveles debe ser no discriminatoria, o sea, accesible a todos, especialmente a los grupos más vulnerables de hecho, y de derecho, sin discriminación por ninguno de los motivos prohibidos, y refuerza el carácter inmediato y no condicionado por los recursos que tiene la obligación de no discriminar en el ámbito de la educación. Esto se enmarca en el principio de no discriminación que atraviesa y permea los derechos reconocidos en el ordenamiento internacional, siendo la principal norma en relación a la idea de discriminación el artículo $2^{\circ} .2^{\circ}$ que en lo general se refiere a las medidas que deben adoptar los Estados, por separado o a través de la asistencia y cooperación internacionales para lograr la plena efectividad de los derechos que reconoce el PIDESC

Resolución 1998/33, de la Comisión de Derechos Humanos.

Resolución 8/4, del Consejo de Derechos Humanos.

8 Creado por la Resolución 1985/17 del Consejo Económico y Social (ECOSOC) para vigilar la implementación del Pacto.

19 Doc. NU E/C.12/1999/10. 


\author{
y sobre el que ha habido un importante desarrollo en el trabajo del órgano de control \\ respectivo y de otras instancias internacionales ${ }^{20}$.
}

20 Como se ha apuntado, con base en su naturaleza, las obligaciones jurídicas que asumen los Estados frente a los derechos económicos, sociales y culturales se presume por muchos que son diversas a aquellas adoptadas para la garantía de los derechos civiles y políticos. Al respecto, el Comité de Derechos Económicos, Sociales y Culturales ha dicho en su Observación General No 3, de 14 de diciembre de 1990, que si bien se contempla una realización paulatina teniendo en cuenta las restricciones derivadas de la limitación de recursos con que cuente el Estado obligado, existen obligaciones en el Pacto que tienen efecto inmediato y una de ellas es que los Estados se comprometen a garantizar que los derechos pertinentes se ejercerán sin discriminación (Doc. NU E/1991/23). lo que transforma esta obligación en una de comportamiento, idea reforzada en 2009 al señalar en la Observación General $N^{\circ} 20$ que la no discriminación es una obligación inmediata y de alcance general en el Pacto (Doc. NU E/C.12/GC/20, párrafo 7). El mismo Comité se ha encargado también de establecer que la enumeración de criterios de discriminación no es exhaustiva y por consiguiente deben también impedirse otras formas de discriminación injustas que afecten el ejercicio de los derechos del Pacto (Doc. NU E/C.12/GC/20, párrafo 15), idea que se refuerza con la mencionada Observación General N²0, que bajo el epígrafe "Motivos prohibidos de discriminación" agrupa el desarrollo de aquellos "motivos expresos" y de todos los que se incluyen en la expresión "otra condición social", desarrollando acá la discapacidad, la edad, la nacionalidad, el estado civil y la situación familiar, la orientación sexual y la identidad de género, el estado de salud, el lugar de residencia y la situación económica y social (Doc. NU E/C.12/GC/20, párrafos 18 al 35), constituyéndose así en un instrumento que da cuenta de una recepción ampliada de los motivos que no se consagran expresamente en el derecho internacional convencional. Asimismo, manteniendo plena vigencia al fin de la primera década del siglo XXI ha dicho el Comité en el año 2000 (Doc. NU E/C.12/2000/13), recogiendo los Principios de Limburgo de 1986 y las Directrices de Maastricht de 1997, que deben terminarse las discriminaciones de iure y de facto que afecten el goce de esta clase de derechos. Además, que el Pacto no sólo obliga a los Estados a desistir de cualquier comportamiento discriminatorio y a modificar las leyes y prácticas que permitan la discriminación, sino que también establece el deber de los Estados parte de prohibir a los particulares y a los organismos (terceros) practicar la discriminación en cualquiera esfera de la vida pública (Folleto Informativo No.16 (Rev.1) -Comité de Derechos Económicos, Sociales y Culturales). Esto es lo que se conoce como el "efecto horizontal" de las normas de no discriminación y que tiene una conexión notoria y notable con el derecho a la educación, especialmente en sistemas que otorgan un importante rol a los particulares desde la proclamación de la libertad de enseńanza. Este desarrollo queda complementado con la consideración de la definición que aporta la Convención de la UNESCO relativa a la lucha contra las discriminaciones en la esfera de la enseñanza de 1960 y sobre la que se ha construido la definición en el derecho internacional. Esta Convención en su artículo $1^{\circ}$ proporciona una definición de discriminación en el ámbito de la enseñanza. "A los efectos de la presente Convención, se entiende por "discriminación" toda distinción, exclusión, limitación o preferencia fundada en la raza, el color, el sexo, el idioma, la religión, las opiniones políticas o de cualquier otra indole, el origen nacional o social, la posición económica o el nacimiento, que tenga por finalidad o por efecto destruir o alterar la igualdad de trato en la esfera de la enseñanza y, en especial: a. Excluir a una persona o a un grupo del acceso a los diversos grados y tipos de enseñanza; $b$. Limitar a un nivel inferior la educación de una persona o de un grupo; c. A reserva de lo previsto en el artículo 2 de la presente Convención, instituir o mantener sistemas o establecimientos de enseñanza separados para personas o grupos; o d. Colocar a una persona o a un grupo en una situación incompatible con la dignidad humana". Como se aprecia, incluye un listado -no cerrado- de ejemplos que constituyen discriminación; al establecer obligaciones positivas y negativas para los Estados y al matizar lo preceptuado en el artículo $1^{\circ}$.c. en relación a instituir o mantener sistemas o establecimientos de enseńanza separados para personas o grupos. Sobre esto último, efectivamente en el artículo $2^{\circ}$. se matiza esa prohibición y permite: i) sistemas de enseñanza separados para los alumnos de sexo masculino y para los de sexo femenino sobre una base equivalente; ii) sistemas de enseñanza separados por motivos de orden religioso o lingüístico, que proporcionen una enseñanza conforme a los deseos de los padres o tutores legales de los alumnos, con carácter facultativo y si la enseñanza en ellos proporcionada se ajusta a determinadas normas; iii) establecimientos de enseñanza privados, siempre que su finalidad no sea la de lograr la exclusión de cualquier grupo, sino la de añadir nuevas posibilidades de enseñanza a las que proporciona el poder público, bajo ciertas condiciones. Este artículo no hace mención a medidas especiales de discriminación, sino que se limita a determinar en qué circunstancias no se considera que la existencia de sistemas de enseñanza separados constituye una discriminación. Además, no prevé explícitamente escuelas públicas especiales. Otro gran aporte de esta definición es considerar que son discriminatorias tanto las prácticas que tienen "por finalidad" como las que tienen "por efecto" destruir o alterar la igualdad de trato, lo que es una cabida en el ámbito positivo a la idea de "discriminación indirecta". 
En otros aspectos a destacar, ha trabajado el Comité de los DESC en dar contenido normativo al artículo 13, por ejemplo en lo relativo a los propósitos y objetivos de la educación, sentando la idea de que "la educación debe orientarse hacia el pleno desarrollo de la personalidad humana" y de que los Estados Partes tienen la obligación de velar por que la educación se adecue a los propósitos y objetivos expuestos en el párrafo 1 del artículo 13, interpretados a la luz de la Declaración Mundial sobre Educación para Todos (Jomtien), la Convención sobre los Derechos del Niño, la Declaración y Plan de Acción de Viena, y el Plan de Acción para el Decenio de las Naciones Unidas para la educación en la esfera de los derechos humanos, textos todos que tienen grandes coincidencias con el párrafo 1 del artículo 13 del Pacto, pero también incluyen elementos que no están contemplados expresamente en él, por ejemplo, referencias concretas a la igualdad entre los sexos y el respeto del medio ambiente, que son nuevos elementos que están implícitos y reflejan una interpretación contemporánea de tal párrafo del artículo 13, dando como argumento a la opinión del Comité el amplio apoyo que los textos que se acaba de mencionar han recibido en todas las regiones del mundo ${ }^{21}$, describiendo también el contenido que han de tener cada uno de los niveles de enseñanza.

Ahora bien, en los ámbitos regionales la labor no es menor a la promovida por las Naciones Unidas y sus órganos. Específicamente quedándome en el continente, todo desarrollo sobre los derechos humanos parte por la Declaración Americana de Derechos y Deberes del Hombre que en mayo de 1948 ya consagraba un catálogo no vinculante de derechos, considerando varios de contenido social, entre ellos la educación en el artículo XII ${ }^{22}$ y sin hacer la dicotomía que luego se reflejó en los instrumentos vinculantes entre derechos civiles y políticos por un lado, y sociales por otro.

Efectivamente, cuando en 1969 se adopta la Convención Americana de Derechos Humanos, conocida como Pacto de San José de Costa Rica, se asumiría la división, estableciendo derechos de los llamados "de primera generación", dejando sólo el artículo 26 -que constituye el Capítulo III de la Convención- para refererise a los derechos sociales, en una norma que ha tenido más bien un carácter programático al consagrar la obligación de desarrollar progresivamente los derechos económicos, sociales y culturales: "Los Estados Partes se comprometen a adoptar providencias, tanto a nivel interno como mediante la cooperación internacional, especialmente económica y técnica, para lograr progresivamente la plena efectividad de los derechos que se derivan de las normas económicas, sociales y sobre educación, ciencia y cultura, contenidas en la Carta de la Organización de los Estados Americanos, reformada por el Protocolo de Buenos Aires, en la medida de los recursos disponibles, por vía legislativa u otros medios apropiados".

21 Doc. NU E/C.12/1999/10, párrafos $4^{\circ}$ y $5^{\circ}$.

22 "Toda persona tiene derecho a la educación, la que debe estar inspirada en los principios de libertad, moralidad y solidaridad humanas. Asimismo tiene el derecho de que, mediante esa educación, se le capacite para lograr una digna subsistencia, el mejoramiento del nivel de vida y para ser útil a la sociedad. El derecho de educación comprende el de igualdad de oportunidades en todos los casos, de acuerdo con las dotes naturales, los méritos y el deseo de aprovechar los recursos que puedan proporcionar la comunidad y el Estado. Toda persona tiene derecho a recibir gratuitamente la educación primaria, por lo menos". 
Esta norma, susceptible de ser analizada desde diversas ópticas, ha motivado en parte una notable jurisprudencia de la Corte Interamericana de Derechos Humanos que ha buscado dar alcance a los derechos sociales en su vinculación con otros derechos, contrariando a fin de cuentas la calificación de que no sería más que una norma de carácter programático ${ }^{23}$.

Siguiendo a Abrahamovic y Rossi ${ }^{24}$, se puede decir que sobre el artículo 26 y su verdadero alcance ha habido dos posiciones extremas. De un lado, quienes han intentado privarla de todo carácter operativo, considerándola una mera expresión de principios para la acción futura de los Estados. Por el otro lado, quienes han tenido la tentación de introducir por vía de este artículo un verdadero catálogo de derechos sociales que es claro que los Estados partes no tuvieron intenciones de considerar en un sistema diseñado para la tutela de derechos civiles y políticos, tratando así de dar justiciabilidad plena a los derechos sociales. Frente a ambas, los autores se inclinan por una posición que estima que del artículo surgen verdaderos derechos pero sin que se pueda llegar al extremo de pasar por la voluntad de los Estados, reconociendo entonces un catálogo de derechos que sí estarían cubiertos por la norma. Situados en la posición que estima que la norma habla de "derechos" y que remite a aquellos establecidos en la Carta de la OEA, sobre la base de las reglas de interpretación de los tratados, el principio del consentimiento y el objetivo final de tutela que persigue el Pacto de San José de Costa Rica, señalan que no pudo ser otro el ánimo de los Estados más que el de obligarse por las normas de carácter económico, social y cultural que se infieren de la Carta. Específicamente apelan a una labor de interpretación para entender cuáles serían los derechos de este tipo que quedarían protegidos al estar implícitos en dicho instrumento, dando como ejemplos ciertos derechos laborales básicos, como las condiciones dignas de trabajo y el salario justo, y el derecho a la educación, en este caso sobre la base de lo que dispone el artículo 49 de la Carta de la $\mathrm{OEA}^{25}$, norma según la cual la educación primaria debe ser obligatoria y gratuita; la educación media debe extenderse progresivamente a la mayor parte posible de la población; y la educación superior debe estar

23 Interesantes desarrollos en este sentido se encuentran en los casos Baena Ricardo y otros (270 trabajadores) con Panamá (sentencia de 2 de febrero de 2001); Cinco Pensionistas con Perú (sentencia de 12 de septiembre de 2005) y el de Trabajadores Cesados del Congreso (Aguado Alfaro y otros) con Perú (sentencia de 24 de noviembre de 2006). Sentencias disponibles en: http://www.corteidh.or.cr/casos.cfm. Sobre el tema y otros desarrollos en el sistema interamericano a favor de los DESC junto a una crítica sobre el trabajo de la Corte en este ámbito véase Melish, T.J., "El litigio supranacional de los derechos económicos, sociales y culturales: avances y retrocesos en el Sistema Interamericano", Programa de Cooperación sobre Derechos Humanos México-Comisión Europea, México, Primera edición, diciembre 2005.

24 Abrahamovic, V. y Rossi, J., "La tutela de los derechos económicos, sociales y culturales en el artículo 26 de la Convención Americana de Derechos Humanos", en Revista Estudios Socio -Jurídicos, abril, volumen 9, número especial, Universidad del Rosario, Bogotá, Colombia, 2007, p. 37.

25 "Los Estados miembros llevarán a cabo los mayores esfuerzos para asegurar, de acuerdo con sus normas constitucionales, el ejercicio efectivo del derecho a la educación, sobre las siguientes bases: a) La educación primaria será obligatoria para la población en edad escolar, y se ofrecerá también a todas las otras personas que puedan beneficiarse de ella. Cuando la imparta el Estado, será gratuita; b) La educación media deberá extenderse progresivamente a la mayor parte posible de la población, con un criterio de promoción social. Se diversificará de manera que, sin perjuicio de la formación general de los educandos, satisfaga las necesidades del desarrollo de cada país, y c) La educación superior estará abierta a todos, siempre que, para mantener su alto nivel, se cumplan las normas reglamentarias o académicas correspondientes". 
abierta a todos, lo cual no obstante no permite dar por establecido el contenido claro de tales derechos, si bien creo que los artículos 47, 48 y 50 pueden contribuir en tal sentido al establecer al menos ciertas directrices a los Estados, como la erradicación del analfabetismo o la cooperación internacional en materia educacional.

Ahora bien, teniendo presentes los alcances posibles que puede tener el artículo 26 del Pacto para la garantía de los derechos sociales, como la educación desde la lógica interpretativa descrita antes, hay que tener presente también que el 17 de noviembre de 1988 se adoptó en San Salvador el Protocolo adicional que contempla un catálogo de derechos sociales, contemplando derecho de petición para quejas individuales sólo respecto de dos de ellos. Uno es justamente el derecho a la educación que consagra el artículo 13, señalando que debe orientarse hacia el pleno desarrollo de la personalidad humana y del sentido de su dignidad y fortalecer el respeto por los derechos humanos, el pluralismo ideológico, las libertades fundamentales, la justicia y la paz. ${ }^{26}$.

Como se aprecia, respecto al derecho de educación en el sistema interamericano ha habido un desarrollo normativo directo en el Protocolo de San Salvador y bien sería posible pensar en su justiciabilidad por la vía del artículo 26 del Pacto de San José de Costa Rica, lo cual se complementa con la Carta Democrática Interamericana que en su Preámbulo y su artículo 16 establece el vínculo estrecho entre la educación, la democracia, y la erradicación de la pobreza, caracterizando a la educación como "un medio eficaz para fomentar la conciencia de los ciudadanos con respecto a sus propios países $y$, de esa forma, lograr una participación significativa en el proceso de toma de decisiones", y destacando el carácter esencial de que una educación de calidad esté al alcance de todos, incluyendo a las niñas y a las mujeres, las personas que habitan en zonas rurales, y las personas que pertenecen a grupos minoritarios. Estas últimas ideas son especialmente importantes en un continente en que las diferencias de género que afectan a

26 "1. Toda persona tiene derecho a la educación. 2. Los Estados partes en el presente Protocolo convienen en que la educación deberá orientarse hacia el pleno desarrollo de la personalidad humana y del sentido de su dignidad y deberá fortalecer el respeto por los derechos humanos, el pluralismo ideológico, las libertades fundamentales, la justicia y la paz. Convienen, asimismo, en que la educación debe capacitar a todas las personas para participar efectivamente en una sociedad democrática y pluralista, lograr una subsistencia digna, favorecer la comprensión, la tolerancia y la amistad entre todas las naciones y todos los grupos raciales, étnicos o religiosos y promover las actividades en favor del mantenimiento de la paz. 3. Los Estados partes en el presente Protocolo reconocen que, con objeto de lograr el pleno ejercicio del derecho a la educación: a. la enseñanza primaria debe ser obligatoria y asequible a todos gratuitamente; b. la enseñanza secundaria en sus diferentes formas, incluso la enseñanza secundaria técnica y profesional, debe ser generalizada y hacerse accesible a todos, por cuantos medios sean apropiados, y en particular por la implantación progresiva de la enseñanza gratuita; c. la enseñanza superior debe hacerse igualmente accesible a todos, sobre la base de la capacidad de cada uno, por cuantos medios sean apropiados y, en particular, por la implantación progresiva de la enseñanza gratuita; $d$. se deberá fomentar o intensificar, en la medida de lo posible, la educación básica para aquellas personas que no hayan recibido o terminado el ciclo completo de instrucción primaria; e. se deberán establecer programas de enseñanza diferenciada para los minusválidos a fin de proporcionar una especial instrucción y formación a personas con impedimentos fisicos o deficiencias mentales. 4. Conforme con la legislación interna de los Estados partes, los padres tendrán derecho a escoger el tipo de educación que habrá de darse a sus hijos, siempre que ella se adecue a los principios enunciados precedentemente. 5. Nada de lo dispuesto en este Protocolo se interpretará como una restricción de la libertad de los particulares y entidades para establecer y dirigir instituciones de enseñanza, de acuerdo con la legislación interna de los Estados partes". 
las mujeres se agudizan como una brecha más para el adecuado logro de igualdad en el goce del derecho a la educación ${ }^{27}$.

A continuación y presentado de forma general el marco normativo internacional, presentaré las ideas centrales sobre el contenido de la educación desde la perspectiva de la educación "en derechos humanos" para mostrar luego los dos ejemplos que se indicaron en el inicio.

\section{La "idea fuerza" de la educación en derechos humanos. Su origen y una aproximación a su contenido.}

Según parte de la literatura consultada, la idea de la "educación en derechos humanos" tendría como padre al brasilero Paulo Freire, reconocido como uno de los pedagogos más influyentes en la educación en América Latina durante el siglo XX, nutriéndose y creciendo desde sus postulados.

Freire, que vivió entre 1921 y 1997 y fue víctima de un exilio que entre otros lugares lo llevaría a Chile en la década de los 60 , sentó ciertas ideas sobre la necesidad de empoderar a las personas desde su muy particular idea de la "pedagogía de la liberación”, estrechamente ligada a la necesidad de generar una educación popular, de base horizontal y en que el individuo se reencuentre con su dignidad en cuanto creador y participante de la cultura y la sociedad en que vive. Como reconoce Magendzo ${ }^{28}$, seguramente Freire no la llamó así, pero en sus ideas está el origen de la educación en derechos humanos, en el sentido de crear sujetos de derechos, como parte central de un proceso educativo ${ }^{29}$.

Esta educación en derechos humanos es un paradigma que se viene trabajando por lo menos hace dos décadas en este lado del mundo. Al trabajo civil realizado por instituciones como el Instituto Interamericano de Derechos Humanos de San José de Costa Rica (IIDH) y de investigadores como el chileno Abraham Magendzo, se han sumado hace unos años la UNESCO y la OEA, quienes por diversos medios han

27 Sobre este tema puede consultarse el documentado trabajo de 2011 de la Comisión Interamericana de Derechos Humanos "El trabajo, la educación y los recursos de las mujeres: la ruta hacia la igualdad en la garantía de los derechos económicos, sociales y culturales" (Doc. OEA/Ser.L/V/II.143 Doc. 59, 3 noviembre 2011), que ha establecido como temas prioritarios en la relación mujeres y derecho a la educación: la igualdad en la educación y la correlación entre niveles educativos y el acceso al mercado laboral; la situación de sectores en particular riesgo a violaciones de sus derechos humanos; los currículos; la situación de las niñas embarazadas; las formas de violencia contra las mujeres en las escuelas y mecanismos de denuncia y la situación relacionada con las estadísticas e indicadores, estableciendo obligaciones que se consideran inmediatas para los Estados. Específicamente véanse sobre dichos temas y la situación continental los párrafos 170 a 245 .

28 Magendzo, A. "Conversaciones y tensiones en torno a la educación en derechos humanos: sobre qué conversamos y qué nos problematiza”, Conferencia Magistral 2002 -2003 de la Cátedra UNESCO de Educación para la Paz, Universidad de Costa Rica, San José, Costa Rica, Primera Edición 2006, p. 10.

29 Se reconoce que el pensamiento principal de Freire está recogido en sus obras "La Educación como práctica de la libertad", escrita en 1967; y "Pedagogía del Oprimido", publicado en español e inglés en 1970. 
ido abriendo espacio para que el tema se transforme en eje de la comprensión que los Estados deberían tener del derecho a la educación.

Así, en conjunto con la Oficina del Alto Comisionado de las Naciones Unidas para los Derechos Humanos la UNESCO viene trabajando en el "Plan de Acción del Programa Mundial para la educación en derechos humanos” y la OEA en el llamado "Pacto Interamericano por la Educación en Derechos Humanos", iniciativas a las que me referiré en el apartado siguiente.

Por ahora quiero detenerme en la idea misma de educación en derechos humanos para tratar de darle algunos límites a su contenido que sirvan para entenderla y mirarla como algo real y no simplemente académico o teórico.

Buscando entre los pocos autores que de ella han escrito en el medio local, surge prontamente que la idea nace asociada a la búsqueda de ayuda para el "nunca más" frente a las crisis institucionales vividas por este lado del planeta en las últimas décadas del siglo XX y las muchas violaciones a derechos ocurridas en esos contextos. Si se quiere, nace la idea vinculada a la necesidad de formar una memoria histórica en las sociedades en que sean las propias personas quienes participen activamente en la construcción de un nuevo capital humano que, al futuro, nunca más sea capaz de llegar a estados en que el respeto por la dignidad humana es olvidado y sacrificado al extremo por otros fines. Nace entonces relacionada al trabajo desde la propia sociedad civil a través de movimientos sociales, de hombres y mujeres trabajadores, de estudiantes, de mujeres, que levantaron la voz para luchar contra la dominación a través del diálogo y su participación como sujetos de sus derechos.

Por cierto, parece que la propia UNESCO también busca el "nunca más” en la promoción de la educación en derechos humanos cuando llama a los Estados de las Naciones Unidas a transmitir las lecciones del holocausto a las generaciones futuras con miras a prevenir cualquier recurrencia de genocidio. Efectivamente en su Resolución 61/255, sobre la negación del Holocausto mediante la educación, aprobada en 2007 en la 34 a . Reunión de la Conferencia General, acoge con satisfacción el establecimiento por el Secretario General de un programa de divulgación sobre el tema "El Holocausto y las Naciones Unidas", y acoge con satisfacción también la inclusión por los Estados Miembros en sus programas educativos de medidas para hacer frente a los intentos de negar el Holocausto o restarle importancia, e insta a todos los Estados Miembros a que rechacen sin reservas cualquier negación del Holocausto como hecho histórico, en su totalidad o en parte, o cualesquiera actividades encaminadas a tal $\mathrm{fin}^{30}$.

En este sentido, pese a lo difuso, vago o excesivamente teórico que puede parecer el concepto y la cercanía que tiene con otros igualmente invocados desde hace mucho tiempo como "educación para la paz", "educación para la democracia" o las cuestionadas "educación para la ciudadanía" o "educación cívica" (que asustan a quienes creen que sólo los padres pueden decidir qué se enseña a sus hijos sobre política en la vida 
pública, sobre principios morales y éticos, sobre la fe y la vida más allá de la muerte, o sobre las distintas formas de familia, de uniones afectivas entre personas o de decisiones para la vida sexual, por ejemplo) todos evidentemente muy conectados a la idea de "educación en derechos humanos"31, lo cierto es que tiene un origen más o menos preciso en un tiempo concreto y en función de los primeros intentos desde la propia sociedad civil para mantener viva la memoria histórica de las sociedades frente a los episodios más tristes que podrá recordar la humanidad respecto del siglo XX, con todo y los grandes avances y mejoras que supuso para el ser humano en tantos ámbitos. En efecto, durante el siglo XX llegamos hasta la Luna y hasta los fondos marinos y oceánicos, pero también llegamos hasta lo más bajo en el respeto por el ser humano.

Así, fácil resulta advertir la conexión evidente con la necesidad de democracias sólidas en que se pueda vivir realmente la ciudadanía inclusiva de todos y todas manteniendo con ello la necesaria paz a que debe aspirar toda sociedad.

Ahora bien, de esta fundamentación original, plenamente vigente si se mira a algunos lados del planeta en lo que va de la primera década del siglo XXI, lo cierto es que el trabajo llevado adelante desde la sociedad civil y desde la institucionalidad internacional permiten entenderla hoy de una manera ampliada y como un paradigma o como una "idea fuerza", imitando el lenguaje de Magendzo, que debe usarse como herramienta en la lucha frente a la indignación y el malestar con que viven y conviven muchas personas en el mundo de hoy.

La erosión cada vez mayor de la capacidad de muchos gobiernos para cumplir una serie de funciones que tradicionalmente le han correspondido frente a los nacionales que los han elegido o los han legitimado; el impacto que provoca la globalización en su faceta más visible como es la económica y comercial a través de la integración de mercados y regiones a veces de manera predatoria para los más pequeńos; los cambios radicales que las innovaciones en ciencia y tecnología provocan en la generación y en la transmisión del conocimiento, las ideas y los valores; la consolidación de amenazas no convencionales a la seguridad como el terrorismo en gran escala, el porte de armas ligeras, los fundamentalismos religiosos o políticos, o las múltiples pandemias de este siglo, están planteando desafíos para los Estados, principalmente para aquellos que no han alcanzado un grado suficiente de desarrollo, que les permita enfrentar el escenario contemporáneo y sus consecuencias.

De hecho, estos desafíos son los que han tomado en el último tiempo la forma de nuevos movimientos sociales, agrupados en torno a la común sensación de "indignación" ante la realidad de este mundo; sea motivados por la común pertenencia a un grupo vulnerable, sea unidos por la lucha a favor de una causa común como mayores cuotas de participación política o reforma a la educación, sea unidos por el deseo de construir una sociedad civil que goce en verdad de cuotas de autonomía. En último

31 Véase un interesante trabajo sobre el tema en general en Maiztegui, C. y Eizaguirre, M., Ciudadanía y educación: de la teoría a la práctica, Cuadernos Deusto de Derechos Humanos, Número 50, Universidad de Deusto, Bilbao, 2008 . 
término, motivados por avanzar hacia sociedades más justas, equilibradas y menos concentradas en el ejercicio de poder político y económico.

Sin duda frente a este escenario las soluciones no son mágicas ni pueden emanar sólo de los Estados o sólo de los actores civiles. Debe haber un trabajo conjunto y en ese cruce de caminos el paradigma de la educación en derechos humanos puede entrar y jugar un rol relevante si creemos en ella.

Por muchos años la lucha fuera de las fronteras nacionales se ha centrado en tratar de abrir nuevos caminos para que las personas puedan ejercer y reclamar sus derechos contra los Estados en casos concretos de vulneraciones, a través de la creación de sistemas formales de protección de derechos y cuando los recursos domésticos no existen o son ineficaces. En ese sentido, puede considerarse un éxito la experiencia que se ha logrado en América a través de la Comisión y la Corte Interamericana de Derechos Humanos y en Europa, a través del Tribunal Europeo de Derechos Humanos.

Específicamente sobre el derecho a la educación y sus garantías, situada en ese capítulo mayor que supone los problemas de justiciabilidad de los derechos económicos, sociales y culturales, los avances desde el derecho internacional son notables y notorios como para no poder seguir argumentando en imprecisión de contenido, su carácter relativo o la escasez de recursos financieros frente a su respeto y garantía, a pesar de que la lógica tradicional ha impedido su entrada directa en la labor jurisprudencial de tales tribunales.

Pero ello claramente no es suficiente y el desafío sigue vivo cuando de los derechos económicos, sociales y culturales se trata. Como enfatiza una autora: "El desafio es construir una sociedad en la que los derechos humanos sean su fundamento ético y funcionen como pautas tanto para la vida política como cotidiana, que regulen las conductas de las personas y de los ciudadanos" 32 .

Resulta más o menos fácil afirmar entonces que la educación es una de las tantas herramientas que se deben usar si queremos de verdad avanzar en terminar con la pobreza, la exclusión, la violencia y las injusticias y, en ese sentido, parece hoy casi una obviedad afirmar que las sociedades necesitan personas educadas desde los niveles básicos o primarios para facilitar el ejercicio de la ciudadanía al contar con conocimiento sobre instituciones, procesos y participación politica, y avanzar en desarrollo humano al aumentar por medio de la educación el despliegue de la potencialidad de capacidades de cada cual. Ya en 1990 los Estados reconocieron estas ideas en la Declaración Mundial sobre Educación, emanada de la Conferencia Mundial "Educación para todos", señalando que la educación es un derecho fundamental de todos, hombres y mujeres, de todas las edades y en el mundo entero; reconociendo que la educación puede contribuir a lograr un mundo más seguro, más sano, más próspero y ambientalmente más puro,

32 Mujica, R.M. "Herramientas y Metodologías para la Educación en Derechos Humanos", en Libro Educación en Derechos Humanos, Klainer, E. y otros, Colección Investigación y Análisis, Comisión de Derechos Humanos del Distrito Federal, México, 2007, p. 45. 
y que al mismo tiempo favorece el progreso social, económico y cultural, la tolerancia y la cooperación internacional; y declarándose conscientes de que la educación es una condición indispensable, aunque no suficiente, para el progreso personal y social.

No obstante estos reconocimientos, que poca vigencia han perdido dos décadas después, por años los sistemas educativos se han seguido centrando en los currículos, los programas de estudio y los conocimientos formales; en la adquisición de ciertos contenidos -en cada uno de los niveles educativos- que luego ayudarán a la meta máxima que será un buen futuro profesional y laboral. "En términos generales, la educación no se dirige a darle un sentido humano a la vida sino, por el contrario, sólo busca insertar a las personas en un mundo globalizado, cada vez más individualista y competitivo" ${ }^{33}$. Es decir, se ha mirado más que nada como instrucción y aprendizaje, en distintos niveles y etapas de la vida, procurando dar a cada una sus propias características de mínimos, adaptables a cada cultura y procurando la progresividad en los diversos niveles educativos, dejando en un segundo plano el trabajo por conjugar de mayor y mejor forma este "derecho a la educación" con la idea de "educar en derechos".

El propio Comité de los Derechos Económicos, Sociales y Culturales ya dejó sentada esta idea claramente en 1999: "1. La educación es un derecho humano intrínseco y un medio indispensable de realizar otros derechos humanos. Como derecho del ámbito de la autonomía de la persona, la educación es el principal medio que permite a adultos $y$ menores marginados económica y socialmente salir de la pobreza y participar plenamente en sus comunidades. La educación desempeña un papel decisivo en la emancipación de la mujer, la protección de los niños contra la explotación laboral, el trabajo peligroso y la explotación sexual, la promoción de los derechos humanos y la democracia, la protección del medio ambiente y el control del crecimiento demográfico. Está cada vez más aceptada la idea de que la educación es una de las mejores inversiones financieras que los Estados pueden hacer, pero su importancia no es únicamente práctica pues disponer de una mente instruida, inteligente y activa, con libertad y amplitud de pensamiento, es uno de los placeres y recompensas de la existencia humana" ${ }^{44}$ (el destacado es mío).

Situada en esta consideración última de la educación que hace el CDESC es desde donde el paradigma de la educación en derechos humanos puede entrar a jugar, entendiendo que esta forma de trabajar el derecho a la educación tiene por objeto -siguiendo en esto a la extinta Comisión de Derechos Humanos de la ONU_ "fomentar el entendimiento de que cada persona comparte la responsabilidad de lograr que los derechos humanos sean una realidad en cada comunidad y en la sociedad en su conjunto. En ese sentido, contribuye a la prevención a largo plazo de los abusos de los derechos humanos y los conflictos violentos, a la promoción de la igualdad y el desarrollo sostenible y al aumento de la participación de las personas en los procesos de adopción de decisiones dentro de los sistemas democráticos" 35 .

\footnotetext{
Mujica, R.M. "Herramientas y Metodologías para la Educación en Derechos Humanos" (cit.) p. 45.

Doc. NU E/C.12/1999/10 (1999), párrafo 1.

Resolución 2004/71 de la Comisión de Derechos Humanos, de 21 de abril de 2004, párrafo 4 del Preámbulo.
} 
En palabras de la UNESCO ${ }^{36}$, la educación en derechos humanos puede definirse como el conjunto de actividades de aprendizaje, enseñanza, formación e información orientadas a crear una cultura universal de los derechos humanos con la finalidad de: a) fortalecer el respeto de los derechos humanos y las libertades fundamentales; b) desarrollar plenamente la personalidad humana y el sentido de la dignidad del ser humano; c) promover la comprensión, la tolerancia, la igualdad entre los géneros y la amistad entre todas las naciones, los pueblos indígenas y las minorías; d) facilitar la participación efectiva de todas las personas en una sociedad libre y democrática en la que impere el Estado de derecho; e) fomentar y mantener la paz; y f) promover un desarrollo sostenible centrado en las personas y la justicia social.

En síntesis, de lo que se trata cuando se sostiene esta idea como paradigma es defender el objetivo de generar modelos educativos integrales, donde los derechos humanos y su respeto y promoción permeen todo el proceso educativo en los diversos niveles y sea parte a su vez de la relación que se da entre todos los actores involucrados, de manera de generar aptitud en las personas para aplicar y defender los derechos en sus vidas cotidianas y en todas las esferas de sus relaciones, por medio de comportamientos conformes con valores básicos para la buena convivencia como la igualdad y no discriminación, la libertad -con sus límites, claramente- y desde el respeto a las características de interdependencia, indivisibilidad y universalidad de los derechos. Es decir, es mucho más que enseñar a unos cuantos "favorecidos" por la carrera que han elegido cuáles son los derechos que tienen el carácter de "fundamentales" en su Constitución y cuáles son las garantías del ámbito interno y del internacional y, por cierto, es mucho más que un solo desarrollo intelectual. Es un vehículo entre la norma -a veces alejada de los individuos y sus realidades- y la vida común y corriente de todos y todas.

Ahora bien, ¿`cómo se logra esto?

La UNESCO ha señalado que la educación en derechos humanos abarca tres ámbitos ${ }^{37}$ :

a) Conocimientos y técnicas: aprender acerca de los derechos humanos y los mecanismos para su protección, así como adquirir la capacidad de aplicarlos de modo práctico en la vida cotidiana; b) Valores, actitudes y comportamientos: promover los valores y afianzar las actitudes y comportamientos que respeten los derechos humanos; y c) Adopción de medidas: fomentar la adopción de medidas para defender y promover los derechos humanos.

Me parece que las tres esferas deben trabajarse relacionadamente y desde los primeros niveles formales de educación, debiendo participar diversos actores que se aspira a su vez ya vengan formados en el mismo paradigma, estando allí el desafío para el mediano y largo plazo.

En esa lógica se insertan a mi modo de ver el Plan de Acción que viene desarrollando la UNESCO y que al año 2011 está centrado en la educación superior y sus actores; 
y, por su lado, el trabajo de la Organización de Estados Americanos por medio del Pacto Interamericano por la Educación en Derechos Humanos, que nace como un acuerdo de voluntades entre los miembros de la comunidad interamericana de derechos humanos, aprobado por la Asamblea General en Lima, Perú, en junio de 2010.

A ambas iniciativas me referiré descriptivamente en el apartado siguiente.

\section{El reconocimiento en la institucionalidad internacional de la educación en derechos humanos. Los ejemplos de la UNESCO y del Sistema Interamericano.}

El 10 de diciembre de 2004, por recomendación de la Comisión de Derechos Humanos y el Consejo Económico y Social, la Asamblea General de las Naciones Unidas proclamó el "Programa Mundial para la educación en derechos humanos" a fin de que comenzara el $1^{\circ}$ de enero de 2005 su labor de fomento de la realización de programas de educación en derechos humanos en todos los sectores ${ }^{38}$.

El Programa Mundial está estructurado en etapas sucesivas a fin de centrar las iniciativas nacionales de educación en derechos humanos en sectores y cuestiones específicas y viene a complementar lo que fue el Decenio de las Naciones Unidas para la educación en materia de derechos humanos (1995-2004).

En efecto el Programa Mundial se ha elaborado sobre la base de una serie de etapas, la primera de las cuales, para el período 2005 -2009, abarcó un Plan de Acción para la educación en derechos humanos en los sistemas de enseñanza primaria y secundaria $^{39}$. La segunda de ellas, prevista para el período 2010 -2014, contempla un Plan de Acción para la educación en derechos humanos en la enseñanza superior y en los programas de formación sobre derechos humanos para funcionarios públicos, fuerzas del orden y personal militar ${ }^{40}$.

Si bien ambos Planes de acción apuntan a objetivos diversos de lo que se estima un proceso continuo, como es la educación, es posible reconocer un contexto común dado por la definición de "educación en derechos humanos", los objetivos del Programa Mundial para esta educación, y los principios rectores de las actividades de educación en derechos humanos ${ }^{41}$.

Así, los objetivos del Programa Mundial para la educación en derechos humanos en todos sus niveles son los siguientes: a) contribuir a forjar una cultura de derechos humanos; b) promover el entendimiento común, sobre la base de los instrumentos internacionales, de los principios y metodologías básicos para la educación en derechos

Resolución 59/113A de la Asamblea General.

Resolución 2004/71 de la Comisión de Derechos Humanos.

Resolución 12/4 del Consejo de Derechos Humanos.

Resolución A/HRC/15/28, párrafos $8^{\circ}$ y $9^{\circ}$. 
humanos; c) asegurar que la educación en derechos humanos reciba la debida atención en los planos nacional, regional e internacional; d) proporcionar un marco colectivo común para la adopción de medidas por todos los agentes pertinentes; e) ampliar las oportunidades de cooperación y asociación en todos los niveles; y f) examinar, evaluar y apoyar los programas de educación en derechos humanos existentes, poner de relieve las prácticas satisfactorias y proporcionar incentivos para continuarlas o ampliarlas y para crear prácticas nuevas.

Por su parte, los principios rectores de las actividades de educación en derechos humanos orientan a que las actividades educacionales previstas en el Programa Mundial tengan por objeto: a) promover la interdependencia, la interrelación, la indivisibilidad y la universalidad de los derechos humanos, incluidos los derechos civiles, políticos, económicos, sociales y culturales, así como el derecho al desarrollo; b) fomentar el respeto y la valoración de las diferencias, así como la oposición a la discriminación por motivos de raza, sexo, idioma, religión, opiniones políticas o de otra índole, origen nacional, étnico o social, condición física o mental, orientación sexual o por otros motivos; c) alentar el análisis de problemas crónicos e incipientes en materia de derechos humanos, en particular la pobreza, los conflictos violentos y la discriminación, teniendo presentes las rápidas transformaciones que se producen en los ámbitos, político, social, económico, tecnológico y ecológico, a fin de poder encontrar respuestas y soluciones compatibles con las normas relativas a los derechos humanos; d) capacitar a las comunidades y a las personas para que puedan determinar sus necesidades en materia de derechos humanos y hacer efectivos esos derechos; e) desarrollar la capacidad de quienes tienen responsabilidades en ese ámbito (en particular los funcionarios gubernamentales), que están obligados a respetar, proteger y hacer efectivos los derechos humanos de las personas bajo su jurisdicción, a fin de que puedan cumplir esa obligación; f) inspirarse en los principios de derechos humanos consagrados en los distintos contextos culturales, y tener en cuenta los acontecimientos históricos y sociales de cada país; g) fomentar los conocimientos sobre instrumentos y mecanismos de nivel mundial, local, nacional y regional y la capacidad de aplicarlos con el objetivo de proteger los derechos humanos; h) utilizar métodos pedagógicos participativos que incluyan conocimientos, análisis críticos y técnicas para promover los derechos humanos; i) fomentar entornos de aprendizaje y enseñanza sin temores ni carencias, que estimulen la participación, el goce de los derechos humanos y el desarrollo pleno de la personalidad humana; y j) ser pertinentes en la vida cotidiana de los educandos, haciendo que estos participen en un diálogo sobre los medios de transformar los derechos humanos, de una expresión de normas abstractas, a la realidad de sus condiciones sociales, económicas, culturales y políticas.

Bajo esos objetivos y principios rectores comunes, en la actualidad se encuentra en curso la segunda etapa del Programa Mundial para la educación en derechos humanos (2010 -2014): un plan de acción para la educación en derechos humanos en la 
enseñanza superior ${ }^{42} \mathrm{y}$ en los programas de formación sobre derechos humanos para funcionarios públicos, fuerzas del orden y personal militar, centrándose así en estos dos amplios sectores.

El tema es especialmente importante hoy por hoy en los contextos universitarios pues el Programa se refiere específicamente a los programas de formación para el personal docente de la enseñanza superior, así como respecto de los educadores de enseñanza primaria y secundaria fue abarcado en la primera etapa ${ }^{43}$.

Como objetivos concretos se plantea: a) promover la inclusión de la educación en derechos humanos en la enseñanza superior y en los programas de formación para funcionarios públicos, fuerzas del orden y personal militar; b) apoyar la elaboración, adopción y aplicación de estrategias nacionales sostenibles de educación en derechos humanos; c) proporcionar directrices sobre componentes decisivos de la educación en derechos humanos en la enseñanza superior y en los programas de formación para funcionarios públicos, fuerzas del orden y personal militar; d) facilitar la prestación de apoyo por las organizaciones internacionales, regionales, nacionales y locales a las instituciones de educación superior y a los Estados miembros; y e) apoyar el establecimiento de redes de contacto y la cooperación entre las instituciones y organizaciones locales, nacionales, regionales e internacionales, tanto gubernamentales como no gubernamentales.

Tomando como marco y antecedente el trabajo que se viene haciendo internacionalmente por el derecho a la educación, tal como la Declaración Universal de Derechos Humanos; la Convención sobre los Derechos del Niño y las directrices conexas aprobadas por el Comité de los Derechos del Niño (en particular su Observación general No 1 sobre los propósitos de la educación, de $2001^{44}$ ); el Pacto Internacional de Derechos Económicos, Sociales y Culturales y las directrices conexas aprobadas por el Comité de Derechos Económicos, Sociales y Culturales (en particular, su Observación general No 13 sobre el derecho a la educación, de 19995); y la Declaración y Programa de Acción de Viena ${ }^{46}$, entre otros instrumentos ${ }^{47}$, el Plan elabora una serie de estrategias e indica quiénes son los agentes que tendrían que estar a cargo de ellas.

42 Por "enseñanza superior" se entiende "todo tipo de estudios, de formación o de formación para la investigación en el nivel postsecundario, impartidos por una universidad u otros establecimientos de enseńanza que estén acreditados por las autoridades competentes del Estado como centros de enseñanza superior". El sector de la enseñanza superior incluye instituciones de formación y certificación de docentes de todos los niveles, de trabajadores sociales y de profesionales de los ámbitos médico y jurídico. Resolución A/HRC/15/28, párrafo 16.

Resolución A/59/113 B.

Doc.NU CRC/GC/2001/1.

5 Doc. NU E/C.12/1999/10.

46 Doc. A/CONF.157/23.

47 Tales son, la Recomendación de la UNESCO sobre la educación para la comprensión, la cooperación y la paz internacionales y la educación relativa a los derechos humanos y las libertades fundamentales; la Declaración y Plan de Acción Integrado de la UNESCO sobre la educación para la paz, los derechos humanos y la democracia; la Convención de la UNESCO relativa a la Lucha contra las Discriminaciones en la Esfera de la Enseńanza; la Recomendación de la UNESCO sobre la convalidación de los estudios, títulos y diplomas de enseñanza superior y las convenciones regionales conexas; la Recomendación de la UNESCO relativa a la condición del personal docente de la enseñanza superior; la Declaración Mundial de la UNESCO sobre la Educación Superior en el 
Para la elaboración de estrategias parte del reconocimiento de que "Aunque para el disfrute de la libertad académica es imprescindible la autonomía de las instituciones de enseñanza superior, esa categoría de educación, como bien público, debe ser responsabilidad de los gobiernos y recibir apoyo económico de ellos. Las instituciones de enseñanza superior, mediante sus funciones básicas (investigación, enseñanza y prestación de servicios a la comunidad), no solo tienen la responsabilidad social de proporcionar una educación ética a los ciudadanos comprometidos con la construcción de la paz y la defensa de los derechos humanos y los valores de la democracia, sino también de generar un conocimiento global para enfrentarse a los actuales retos en el ámbito de los derechos humanos, como la erradicación de la pobreza y la discriminación, la reconstrucción posterior a los conflictos, el desarrollo sostenible y el entendimiento multicultural' ${ }^{28}$.

En consecuencia, la función de la educación en derechos humanos en la enseñanza superior es fundamental. Como el aprendizaje abarca "no solo los elementos integrantes del plan de estudios, sino también los procesos de enseñanza, los métodos pedagógicos y el marco en el que se imparte la educación", la educación en derechos humanos en la enseñanza superior debe concebirse como un proceso que incluye: a) "Los derechos humanos por conducto de la educación”, a fin de asegurar que todos los componentes y procesos del aprendizaje, incluidos los planes de estudio, los materiales, los métodos y la formación misma conduzcan al aprendizaje de los derechos humanos; b) "Los derechos humanos en la educación", a fin de asegurar que se respeten los derechos humanos de todos los interesados, y el ejercicio de esos derechos, en el sistema de enseńanza superior ${ }^{49}$.

Lo anterior resulta nada menor ni teórico cuando hoy, por ejemplo, en Chile vemos con triste regularidad denuncias de malos tratos y abusos, verbales o físicos, por parte de docentes a estudiantes o también de estudiantes a docentes, recordando sólo para graficar lo que fue el triste episodio del día 29 de agosto de 2011 cuando en la Facultad de Ingeniería de la Universidad de Concepción un grupo de jóvenes encapuchados y armados con una bomba de humo, ingresaron al recinto y atacaron a dos profesores que intentaban dar inicio a un nuevo semestre académico.

A ello podemos sumar una larga lista de hechos que demuestran el desconocimiento a una cultura de respeto de los derechos de los demás en un clima de paz en nuestra sociedad, sumado a un deterioro del respeto a los ejes articuladores de una cultura democrática. Desde la violencia estudiantil, con su más nefasta manifestación hoy conocida como "bullyng", el aumento de pandillas infantiles y juveniles que buscan delinquir e inventar nuevos métodos para ello, llegando a la agresión física y verbal en las casas, las escuelas, las universidades y la propia familia a veces.

Siglo XXI: Visión y Acción; el Comunicado de la Conferencia Mundial de Educación Superior 2009 de la UNESCO titulado "Las Nuevas Dinámicas de la Educación Superior y de la Investigación para el Cambio Social y el Desarrollo"; el Marco de Acción de Dakar sobre Educación para Todos: Cumplir Nuestros Compromisos Comunes, aprobado en el Foro Mundial sobre la Educación en 2000; y el Plan de Aplicación de la Cumbre Mundial sobre el Desarrollo Sostenible.

48 Resolución A/HRC/15/28, párrafo 21.

49 Resolución A/HRC/15/28, párrafo 22. 
Ahora bien, reconociendo el Plan de la UNESCO que si bien hay muchos factores que pueden aportar una contribución, la integración del enfoque de derechos humanos en la enseñanza superior debería incluir la adopción de medidas, como mínimo, en las cinco esferas siguientes: políticas y medidas de aplicación conexas; procesos e instrumentos de enseñanza y aprendizaje; investigación; el entorno de aprendizaje; y educación y perfeccionamiento profesional del personal docente de la enseñanza superior.

Para la acción en estas esferas la UNESCO considera la participación de diversos agentes, indicando que la responsabilidad principal de la aplicación de esta parte del plan de acción compete a los ministerios de educación o de educación superior, que cooperarán con otros departamentos pertinentes del gobierno (por ejemplo, los ministerios de hacienda), así como a las instituciones de enseńanza superior y las escuelas superiores de formación pertinentes, según sus diferentes niveles de responsabilidad y dependiendo del grado de autonomía institucional que tengan ${ }^{50}$.

Sin embargo, se prevé que los agentes mencionados necesitarán colaborar estrechamente con numerosas instituciones y organizaciones nacionales, como los sindicatos del personal docente de la enseńanza superior; los sindicatos y asociaciones de estudiantes; los órganos legislativos, incluidos comisiones y órganos de asesoramiento parlamentarios de educación, desarrollo y educación en derechos humanos; las instituciones nacionales de derechos humanos, como los defensores del pueblo y las comisiones de derechos humanos; las instituciones pertinentes de enseñanza superior que participan en los programas de las Redes UNITWIN y las Cátedras UNESCO; las redes nacionales de universidades y escuelas superiores; las Comisiones Nacionales para la UNESCO; los institutos de investigación de la enseñanza; los centros o institutos nacionales y locales de formación en derechos humanos y de recursos, incluidos los pertenecientes a las instituciones de enseńanza superior; las escuelas superiores de formación del personal docente de la enseñanza superior, en caso de que existan; y las $O N G^{51}$, así como también -aunque se les atribuye un rol si se quiere menor, en lo que creo no sería una buena estrategia- los medios de comunicación; las instituciones religiosas; los dirigentes comunitarios y las instituciones de las comunidades locales; los pueblos indígenas y las minorías; y el sector empresarial ${ }^{52}$.

En segundo término, en este apartado quiero referirme a lo que es el llamado Pacto Interamericano por la Educación en Derechos Humanos que, como se adelantó, se concreta normativamente en junio de 2010 en el marco de la Asamblea General de Lima, Perú ${ }^{53}$.

Esta iniciativa nace en el año 2000 desde el Instituto Interamericano de Derechos Humanos que con respaldo y reconocimiento de la Asamblea General, desarrolló un sistema de indicadores para el monitoreo del progreso del derecho a la educación en

\footnotetext{
Resolución A/HRC/15/28, párrafo 34 .

Resolución A/HRC/15/28, párrafo 35.

Resolución A/HRC/15/28, párrafo 36.

Doc. OEA AG/RES. 2604 (XL-O/10).
} 
derechos humanos, en conformidad a lo establecido en el artículo 13 del Protocolo de San Salvador. Ese esfuerzo se tradujo en el "Informe Interamericano de la Educación en Derechos Humanos" del año 2002, en la "Propuesta Curricular y metodológica para la incorporación de la Educación en Derechos Humanos en la educación formal de nińos y niñas entre 10 y 14 años de edad”, de 2007, documento que la Asamblea General de la OEA recomendó a los Estados implementar ${ }^{54}$.

Con posterioridad los Ministerios de Educación de El Salvador y de la República Oriental del Uruguay se unieron a la cruzada del Instituto Interamericano, recibiendo pronto respaldo de los Ministerios de Educación de Costa Rica, Colombia, República Dominicana y Argentina.

En este ámbito continental el trabajo desde la educación en derechos humanos se ha concentrado fuertemente en la enseñanza escolar, especialmente en el período entre los 10 y 14 años, y se enmarca en el artículo 13 ya citado de manera de desarrollar desde esta iniciativa procesos de orientación y apoyo a los Estados partes y signatarios del Protocolo de San Salvador en el campo de la educación en derechos humanos, por medio de estrategias y de acciones.

La razón de enfocarse principalmente en este grupo etario estaría en que se ha focalizado dicha edad como la fase primordial para la educación en materia de derechos humanos, por un factor cuantitativo y pedagógico. Según el trabajo del IIDH, cerca del 75\% de la población escolar de la región está concentrada en ese período de edad escolar, incluido en la franja que la legislación establece dentro de la educación obligatoria. Por otro lado, agrega, es un grupo etario que transita un momento de crecimiento y desarrollo evolutivo de la personalidad caracterizado por el reconocimiento del otro -la otredad-como distinto y de la realidad social como balance de interacción entre derechos y obligaciones.

En esta base, los ejes fundamentales del Pacto son: 1) el reconocimiento legal del derecho a la educación en derechos humanos, por medio de desarrollos jurídicos necesarios y adecuados que garanticen la vigencia de este derecho; 2) el desarrollo de políticas públicas educativas, a través de la dotación de infraestructura y recursos técnicos en zonas especialmente postergadas, el diseño, adecuación e implementación curricular de forma que refleje los principios del Estado democrático; el abordaje de la exclusión, la discriminación y la extrema pobreza, y mediante la seguridad y la erradicación de la violencia para la solución de los conflictos; 3 ) el fortalecimiento de las condiciones y recursos pedagógicos del sistema educativo para la educación en derechos humanos, por medio de la formación y capacitación continua de docentes y otros agentes educativos que coadyuvan al proceso; las asesorías del Ministerio de Educación para el desarrollo de materiales didácticos y la elección de gobierno escolares y otros medios de participación política estudiantil.

54 Doc. OEA AG/RES. 2466 (XXXIX-O/09). 
Ahora bien, en su cruzada por el tema el Instituto Interamericano de Derechos Humanos, con el objetivo de ayudar a los Estados y a los educadores de la región con herramientas por medio de trabajos teóricos y aplicados para cumplir mejor con sus respectivas misiones, viene desarrollando una serie de Informes desde el año 2002, los que han servido para fortalecer la cooperación y el diálogo entre diversos actores y agentes que trabajan en el campo de la educación en derechos humanos, pero muy en particular los ministerios o secretarías de educación de los 19 Estados firmantes del Protocolo de San Salvador, lo que entrega un verdadero respaldo oficial al trabajo de investigación que viene haciendo esta entidad académica, muy vinculada al sistema interamericano de protección de derechos.

El primer informe examinó el marco legal de la educación en derechos humanos en los países del Pacto. En el año 2003 analizó las variaciones en el diseño y contenido del currículum oficial, modificaciones en los planes, programas y contenidos de algunos niveles educativos. Para el año 2004 el informe se enfocó en los principios, contenidos y orientaciones pedagógicas de los docentes, tanto en su formación inicial como en la capacitación en servicio. El Informe correspondiente al año 2005 trató los progresos de los países en educación en derechos humanos como política de Estado, medidos a través de los planes nacionales en el tema y otros instrumentos desarrollados en los niveles internos. Sobre la base de los cuatro informes anteriores, en 2006 se trabajó sobre factores fundamentales para el propósito de incorporar, mejorar y ampliar la educación en y para los derechos humanos y la vida en democracia en la educación formal que ofrecen los estados. Con el Informe siguiente se dio inicio a una nueva etapa, la cual ha Estado destinada a volver sobre los temas tratados con un mayor nivel de profundidad incorporando un nuevo elemento de carácter transversal para el análisis: la participación democrática del alumnado en la gestión educativa. En los informes de 2008 y 2009 se trabajó sobre currículum y textos escolares, respectivamente. Específicamente el VIII Informe, por ser su objeto de estudio los libros de texto usados por los escolares de entre los 10 y los 14 ańos de edad, los cuales son los instrumentos didácticos por excelencia en nuestros sistemas educativos porque representan tanto la traducción de la propuesta pedagógica que está sintetizada en el currículo oficial como la principal herramienta para los docentes en su trabajo diario dentro del aula, debería ser de particular interés en cuanto además complementa las investigaciones anteriores sobre los contenidos de los programas para los estudiantes del mismo grupo de edad y sirven para obtener una visión de la educación en derechos humanos en el continente a esta fecha ${ }^{55}$.

Los informes del Instituto citado en este ámbito gozan ya de reconocimiento regional como instrumento de especial valor para el diagnóstico y la observación del progreso del derecho de la educación en derechos humanos en el continente, siendo consultados desde las instancias nacionales gubernamentales como desde los actores civiles, y orga-

55 Los informes se encuentran disponibles en el sitio web oficial http://www.iidh.ed.cr/ 
nizaciones internacionales, particularmente la Organización de Estados Americanos, a quien ha servido en su causa mayor de promover los derechos humanos ${ }^{56}$.

\section{Reflexiones finales.}

Situada en la concepción de la educación en derechos humanos como un paradigma que he procurado describir de manera práctica y no como un mero ejercicio intelectual, y conociendo algunas iniciativas internacionales para promoverla, surge como una primera reflexión al mirar la realidad que en muchas partes la educación de hoy en general no está pensada realmente desde este verdadero marco intelectual de los derechos humanos, entendiendo de esta manera el uso de la expresión "paradigma", sino que, muy por el contrario, está lejos de llegar a incorporarlo, ni en el contenido ni en el proceso educativo. De hecho, algunos ni siquiera parecen pensar en la educación como un derecho, sino más como un bien de consumo al que podríamos aplicar sin más las reglas de la oferta y la demanda del mercado ${ }^{57}$.

Si un país aspira a un cambio revolucionario en la educación la propuesta debería por lo menos mirar estos esfuerzos y ver si algo estamos haciendo en los distintos niveles, más allá por cierto de dar mayores recursos a los diversos actores o fiscalizar adecuadamente para que nadie lucre en verdad con la educación, considerando incluso que tal vez las reformas constitucionales o legales que tengan que venir deban ser bastante más profundas que mejoras o adiciones a los numerales 10 y 11 del artículo 19 de la Constitución Política o a la Ley General de Educación.

56 Sin perjuicio de los dos desarrollos expuestos, de la UNESCO y de la OEA, corresponde mencionar que en 2011 se concretó la iniciativa de que la Asamblea General de la ONU adoptara una resolución sobre el tema. Efectivamente en la sesión del 19 de diciembre, se adoptó la "Declaración sobre educación y formación en materia de derechos humanos", acogiendo con ella la aprobación por el Consejo de Derechos Humanos de la Declaración de las Naciones Unidas sobre educación y formación en materia de derechos humanos en su resolución 16/1, de 23 de marzo de 2011. Esta Declaración consagra el derecho de toda persona a poseer, buscar y recibir información sobre todos los derechos humanos y las libertades fundamentales y de tener acceso a la educación y la formación en materia de derechos humanos; establece que la educación y la formación en materia de derechos humanos son un proceso que se prolonga toda la vida y afecta a todas las edades y que están integradas por el conjunto de actividades educativas y de formación, información, sensibilización y aprendizaje que tienen por objeto promover el respeto universal y efectivo de todos los derechos humanos y las libertades fundamentales, contribuyendo así, entre otras cosas, a la prevención de los abusos y violaciones de los derechos humanos al proporcionar a las personas conocimientos, capacidades y comprensión y desarrollar sus actitudes y comportamientos para que puedan contribuir a la creación y promoción de una cultura universal de derechos humanos. Agrega que la educación y la formación en materia de derechos humanos engloban: a) La educación sobre los derechos humanos, que incluye facilitar el conocimiento y la comprensión de las normas y principios de derechos humanos, los valores que los sostienen y los mecanismos que los protegen; b) La educación por medio de los derechos humanos, que incluye aprender y enseńar respetando los derechos de los educadores y los educandos; c) La educación para los derechos humanos, que incluye facultar a las personas para que disfruten de sus derechos y los ejerzan, y respeten y defiendan los de los demás. (Doc. NU A/RES/66/137).

57 Destacada fue la frase del Presidente de la República, don Sebastián Pińera, indicando que la educación “...es un bien de consumo", al inaugurar la sede de un conocido instituto de formación profesional en la comuna de San Joaquín, el 19 de julio de 2011. 
Parece importante recordar acá lo que ha sido uno de los mayores logros de las últimas décadas luego de dos conflictos mundiales: el rescate del valor del ser humano como un ser que puede y está llamado a ser parte del proceso de creación y construcción de su propia vida. Si estamos conscientes de ese logro no se puede sino mirar la educación desde el paradigma de derechos humanos pues como antes dije, siguiendo al Comité de los Derechos Económicos, Sociales y Culturales, “... disponer de una mente instruida, inteligente y activa, con libertad y amplitud de pensamiento, es uno de los placeres y recompensas de la existencia humana" ${ }^{158}$.

Ello no supone tomar sin crítica y sin eventuales reparos todas las iniciativas que desde el mundo internacional institucionalizado o aun desde ámbitos nacionales comparados nos podrían llegar.

Tal vez es justamente lo contrario, de lo que se trataría es debatir y aportar para construir el modelo educativo que cada sociedad con sus particularidades necesita para cumplir con tener en el centro del desarrollo a las personas y construir verdaderos sujetos de sus derechos y no solo sujetos de derecho.

La invitación sería entonces apostar por incorporar esta perspectiva, si se quiere más "humana", en todos los procesos y modelos educativos. Apostar por la planificación y ejecución de un modelo que genere una educación centrada en la persona y el respeto de su dignidad; en el aprendizaje desde la realidad de cada persona considerando que somos sujetos constructores del proceso educativo; en el aprendizaje desde la valoración de los derechos humanos y la democracia a fin de formar ciudadanos participativos, que puedan aportar libre, reflexiva y críticamente al crecimiento social del país, en un marco de participación que fomente el respeto por las diferencias, con tolerancia y paz, que respete las libertades de culto, conciencia, pensamiento y expresión y, por cierto, la de enseńanza. Un modelo en que cada estudiante sepa que la violencia no es ni será herramienta para solucionar una diferencia; que el estudiante de arquitectura y el arquitecto luego sepan que las viviendas han de ser ante todo dignas; que el estudiante de medicina y el médico luego sepan que el paciente tiene el derecho a preguntar y a ser oído. Un modelo en que todo ello pueda conjugarse de forma adecuada con el respeto a la igualdad en la diversidad, a la tolerancia, a libertad de enseñanza y a la libertad de culto o de pensamiento y, por cierto, con aquellos sistemas, como el chileno, que le otorgan a los padres el deber preferente de educar a sus hijos y contemplan una participación fuerte de agentes privados en la construcción de modelos educativos.

Lograr un modelo así por cierto no será fácil ni tarea de pocos, pero educar de este modo debería ser la consigna de la educación mundial, como educación para la paz y la seguridad si se considera que es el principal propósito de la sociedad internacional institucionalizada, y en ella por ejemplo los medios de comunicación y los medios informáticos y tecnológicos, en cuanto formadores de opinión pública, están llamados a cumplir un rol que es del todo relevante, sin perjuicio del rol clave que le toca a los

58 Doc. NU E/C.12/1999/10 (1999), párrafo 1. 
propios estados en esta como en tantas otras materias y los demás actores que se han ido mencionando al referir los modelos UNESCO y OEA.

Por ahora me quedo en el rol del Estado y el de los educadores, y por cierto mirando hacia la realidad chilena, para apostar con algunas ideas sobre qué se podría hacer para caminar en este sentido.

Aunque muchos critiquen o cuestionen el rol del derecho internacional por su real eficacia frente a los temas medulares de la sociedad internacional, lo cierto es me posiciono del lado de quienes creen que Chile debe seguir en el camino que ha trazado con fuerza desde 1990 al insertarse internacionalmente desde el respeto y compromiso con el derecho y los derechos humanos como un eje articulador de su política exterior. En tal sentido, el país debería seguir la recomendación internacional y ratificar el Protocolo de San Salvador, que firmó en 2001 pero no ha ratificado por estar pendiente (y parece sin ningún apuro) la aprobación legislativa. No hay que perder de vista que si bien este acuerdo respeta que conforme con la legislación interna de los Estados partes, los padres tengan derecho a escoger el tipo de educación que darán a sus hijos, ésta debe ser adecuada a los principios que se establecen y que van en la línea de una educación orientada hacia el pleno desarrollo de la personalidad humana y del sentido de su dignidad; que fortalezca el respeto por los derechos humanos, el pluralismo ideológico, las libertades fundamentales, la justicia y la paz; y que capacite a todas las personas para participar efectivamente en una sociedad democrática y pluralista, lograr una subsistencia digna, favorecer la comprensión, la tolerancia y la amistad entre todas las naciones y todos los grupos raciales, étnicos o religiosos y promover las actividades en favor del mantenimiento de la paz. Es decir, una visión de la educación bastante más holístitica y "humanista" que nuestras referencias constitucionales que parecen antes que todo defender a ultranza la libertad de enseñanza y todo lo que ella comprende, tanto para el Estado como para los particulares, sean establecimientos educacionales o padres.

Del mismo modo, así como en un momento de la historia fue actor relevante para alcanzar un acuerdo que vería nacer el Estatuto de Roma y la Corte Penal Internacional (más allá de lo que la historia interna diría luego para que Chile fuera parte de ese sistema), podría transformarse en un promotor activo para que entre en vigor el Protocolo Facultativo al Pacto Internacional de Derechos Económicos, Sociales y Culturales de 10 de diciembre del año 2008, que aún no logra el número de ratificaciones suficientes y está abierto a la firma desde 2009.

Las razones de por qué Chile no cumple en plenitud sus compromisos internacionales en temas de derechos humanos, específicamente en el caso del Protocolo de San Salvador y la regulación del derecho a la educación, podrían presumirse motivadas en una falta de ganas de asumir una obligación en ese sentido que claramente podría llegar a generar un conflicto con el derecho tan marcado y reclamado en Chile de que los padres elijan libremente cómo educar a sus hijos y los establecimientos decidan libremente qué y cómo enseñan. Además, también esto puede tener que ver 
con aquella vieja ya argumentación de los recursos y su escasez. Si así fuera y así lo consideramos, lo curioso es que si bien en un inicio me quise desmarcar de los temas de financiamiento que tanto rondan a las discusiones sobre educación en estos días, si se considera la necesidad de que los Estados comprometan recursos para lograr algún éxito en las estrategias del plan interamericano, por ejemplo, lo cierto es que al final, así como "todos los caminos llevan a Roma"... "todos los caminos llevan a la necesidad de mayores recursos para la educación” ....incluso esta teórica perspectiva de la educación desde los derechos humanos.

No debe olvidarse además que conforme nuestras bases de la institucionalidad se comprende por el artículo $1^{\circ}$ de la Constitución que el Estado está al servicio de la persona humana y que además tiene el deber de contribuir a crear las condiciones sociales que permitan a todos y cada uno de los integrantes de la comunidad nacional su mayor realización espiritual y material posible y que, por lo demás, Chile sí está obligado internacionalmente por la Declaración Universal de Derechos Humanos y por el Pacto Internacional de Derechos Económicos, Sociales y Culturales, el cual por cierto debe leerse en relación al artículo $5^{\circ}$ inciso $2^{\circ}$ de nuestro texto constitucional.

En cuanto a los educadores parece ser que lo primero es situarse desde la convicción, para ser elemento coadyuvante y no obstáculo en el cambio de paradigma. Para eso tal vez habría que tener actitudes y conocimientos.

Actitudes como dejar el egoísmo y aceptar que se forma parte de un proceso en que hay muchos otros actores; dejar prejuicios que a veces llevan a no aceptar a los demás en sus diferencias de todo tipo y comprender que somos diferentes en nuestras personales y particulares características pero iguales en valor y dignidad; tolerar las discrepancias de opinión, pensamiento, creencia y culto, los distintos hábitos y costumbres; apreciar el aporte que cada individuo puede hacer, desde su lugar y creencia a esa sociedad que busca crear sujetos de derechos, todo ello a través del diálogo como primera herramienta. En síntesis, llevar los derechos a la vida del aula y de la institución en que se desarrolla la labor docente, mirando en todo caso toda iniciativa que no siendo propia puede ser imitada o al menos servir de referente para generar una propia estrategia.

Por último, habría que preguntarse, luego de estas reflexiones, si hay "objetivos país" que puedan alcanzarse de manera más fácil siguiendo este enfoque en las discusiones sobre la educación en Chile. Mi propuesta es que sí los hay.

Efectivamente, educando en derechos humanos mejoramos la conciencia sobre los vínculos existentes entre desarrollo, democracia y derechos humanos, ayudando de paso a generar una real conciencia sobre la necesidad de eliminar toda forma de discriminación en el aula y fuera de ella, especialmente hacia aquellos grupos más vulnerables de la sociedad chilena; se ayuda a la construcción de espacios reales y efectivos de ciudadanía que generen herramientas y acciones que fortalezcan a los sujetos y les otorguen verdadera capacidad de intervenir en las decisiones del cuerpo social, dándole espacio real en la vida pública, desde los pequeños espacios locales hasta las políticas públicas que adopte una cierta administración y, por último, si se quiere logramos el 
objetivo de ser un país referente en un tema en que hay consenso mundial como es el de los derechos humanos, al tomar un enfoque verdaderamete positivo para trabajar la educación y su calidad.

\section{BIBLIOGRAFÍA}

ABRAHAMOVIC, V. y Rossi, J. "La tutela de los derechos económicos, sociales y culturales en el artículo 26 de la Convención Americana de Derechos Humanos", en Revista Estudios Socio -Jurídicos, abril, volumen 9, número especial, Universidad del Rosario, Bogotá, Colombia, 2007, pp. 34 -53.

ALVEZ, A., "Análisis crítico de la vigencia normativa de la constitución de 1980, adoptando como ejemplo la educación vinculada al ideal democrático", en Libro "Reflexiones sobre Desarrollo Humano: Derechos, Política y Globalización, Fondo de Publicaciones, Facultad de Ciencias Jurídicas y Sociales, Universidad de Concepción, agosto 2008.

CARBONELL, M., "Breves reflexiones sobre los derechos sociales", en Memorias del Seminario Internacional sobre Derechos económicos, sociales y culturales, Programa de Cooperación sobre Derechos Humanos México - Comisión Europea, México, Primera edición, diciembre 2005.

CONDE, S.L., "Diversidad cultural en la Educación en Derechos Humanos", en Libro Educación en Derechos Humanos, Klainer, E. y otros, Colección Investigación y Análisis, Comisión de Derechos Humanos del Distrito Federal, México, 2007, pp. 75 -97.

CORREA, R., Sobre la libertad de enseñanza y el derecho a la educación, 2006. (Fecha de consulta: 28 de febrero de 2012). Disponible en: http://www.uai.cl/ prontus3 newsletter/site/artic/20060602/pags/20060602103853.html

ESPEJO, N., “Quién debería creer en los derechos económicos, sociales y culturales?”, en Memorias del Seminario Internacional sobre Derechos económicos, sociales y culturales, Programa de Cooperación sobre Derechos Humanos México - Comisión Europea, México, primera edición, diciembre 2005.

KLAINER, R.E., "La Educación para la vida en democracia", en Libro Educación en Derechos Humanos, Klainer, E. y otros, Colección Investigación y Análisis, Comisión de Derechos Humanos del Distrito Federal, México, 2007, pp. 11 -40.

MAGENDZO, A., "Conversaciones y tensiones en torno a la educación en derechos humanos: sobre qué conversamos y qué nos problematiza”, Conferencia Magistral 2002 -2003 de la Cátedra UNESCO de Educación para la Paz, Universidad de Costa Rica, San Juan, Costa Rica, Primera Edición 2006, páginas.

MAGENDZO, A., Pensamiento e ideas -fuerza de la educación en derechos humanos en Iberoamérica, Ediciones SM, Santiago, 2009. 
MAIZTEGUI, C. y Eizaguirre, M., Ciudadanía y educación: de la teoría a la práctica, Cuadernos Deusto de Derechos Humanos, Número 50, Universidad de Deusto, Bilbao, 2008.

MARTÍNEZ DE PISÓN, J., Derechos Humanos: historia, fundamento y realidad, Egido Editorial, 1997.

MELISH, T.J., "El litigio supranacional de los derechos económicos, sociales y culturales: avances y retrocesos en el Sistema Interamericano", Programa de Cooperación sobre Derechos Humanos México - Comisión Europea, México, Primera edición, diciembre 2005.

MUJICA, R.M., "Herramientas y Metodologías para la Educación en Derechos Humanos", en Libro Educación en Derechos Humanos, Klainer, E. y otros, Colección Investigación y Análisis, Comisión de Derechos Humanos del Distrito Federal, México, 2007, pp. 41 -73.

NICOLETTI, J., "La práctica del Derecho Humano a la Educación como constructor de ciudadanía", artículo en el Libro "Cuestiones prácticas de los Derechos Humanos", Compilador: Javier Nicoletti, Editorial de la Universidad Nacional de la Matanza, Buenos Aires, 2008, pp. $101-122$.

NOGUEIRA, H., "Los derechos económicos, sociales y culturales como derechos fundamentales efectivos en el constitucionalismo democrático latinoamericano", en Revista Estudios Constitucionales, Año 7, No 2, 2009, pp. 143-205.

NOGUEIRA, H., Derechos fundamentales y garantías constitucionales; Librotecnia, Santiago, 2010.

NOGUEIRA, H., "Los derechos esenciales o humanos contenidos en los tratados internacional, y su ubicación en el ordenamiento jurídico nacional: doctrina y jurisprudencia”, en Revista Ius et Praxis, año 9, Nº 1, Talca, 2003.

RUIZ -TAGLE VIAL, P. y Correa, S., "El derecho a una educación de calidad", en Anuario de Derechos Humanos, Santiago, Universidad de Chile, Centro de Derechos Humanos, 2007, pp. $173-181$. 